\title{
$\mathrm{PH} \mathbf{8 8}$
}

\section{La memoria del tiempo o el proceso de intervención en la iglesia del Santo Cristo de la Salud de Málaga}

Aurora Villalobos Gómez | arquitecta

URL de la contribución <www.iaph.es/revistaph/index.php/revistaph/article/view/3681>

\section{RESUMEN}

En el año 2009 se firmó un convenio de colaboración entre la Consejería de Cultura de la Junta de Andalucía, el Instituto Andaluz del Patrimonio Histórico, la Fundación Montemadrid y el Obispado de la Diócesis de Málaga para la restauración de la iglesia del Santo Cristo de la Salud de Málaga y su programa iconográfico. Un templo jesuítico de mediados del siglo XVII con una colección de pintura mural, retablos y esculturas relacionados entre sí que constituye un singular documento construido de los principios de la Contrarreforma. Los contenidos del Proyecto de Conservación, redactado por un equipo interdisciplinar del Centro de Intervención del IAPH, fueron presentados en revista PH 79 (agosto, 2011).

En esta ocasión, una vez finalizadas las obras (junio 2013 - noviembre 2014), este artículo aborda el proceso de intervención en la iglesia describiendo las actuaciones realizadas sobre la cubierta, la fachada y el interior del inmueble en materia de conservación, adecuación funcional y musealización de los bienes culturales. Asimismo se reflexiona sobre las aportaciones de un proyecto que, más allá de la obra, ha recuperado desde el presente la memoria del edificio: mejorando su conservación, devolviéndole su presencia urbana y descubriendo un espacio interior ordenado y luminoso.

\section{Palabras clave}

Centro de Inmuebles, Obras e Infraestructuras | Centro de Intervención | Fundación Montemadrid | Iglesia del Santo Cristo de la Salud | Instituto Andaluz del Patrimonio Histórico | Intervención | Jesuitas | Junta de Andalucía. Consejería de Cultura | Málaga | Málaga (Diócesis). Obispado | Musealización | Patrimonio arquitectónico | Programa de Conservación del Patrimonio Histórico Español | 


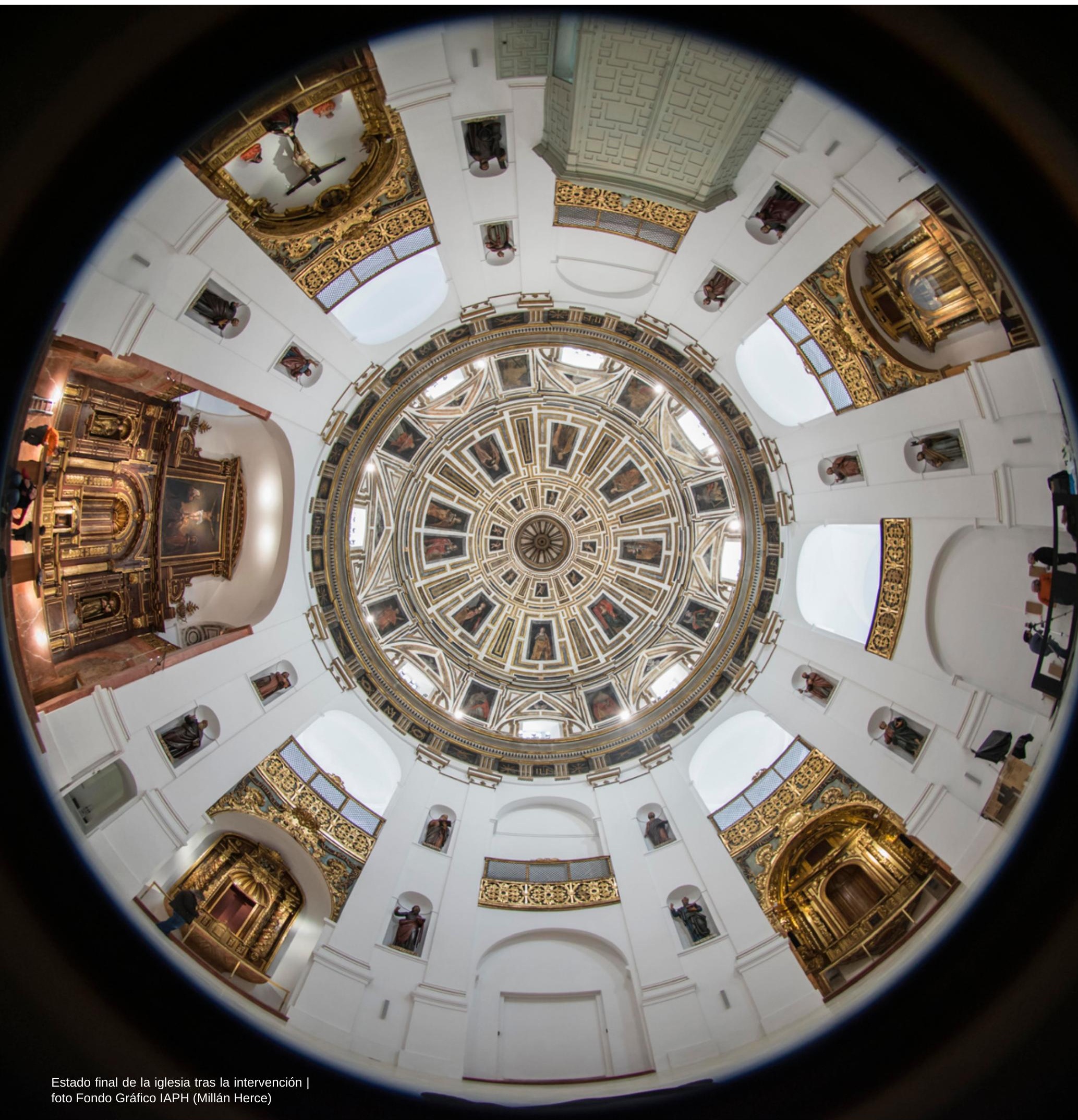




\section{DEL PROYECTO A LA OBRA}

\section{La estrategia del programa de conservación}

El proyecto de intervención en la iglesia forma parte de un programa general denominado Proyecto de conservación del programa iconográfico de la iglesia del Santo Cristo de la Salud de Málaga que ha tenido por objeto la conservación integral, puesta en valor y difusión de este bien de interés cultural integrado por un bien inmueble y una valiosa colección de bienes muebles asociados. Desde el principio, se planteó actuar sobre la diversidad desde la unidad, desarrollando una estrategia de gestión que permitiera planificar, coordinar y supervisar adecuadamente todos los procesos, a favor de una más ágil tramitación administrativa y adecuada distribución de las competencias profesionales marcadas por la legislación competente en vigor. Eso se ha traducido en que el proyecto de conservación se ha desarrollado en dos líneas complementarias:

> Proyecto de conservación de los bienes muebles: para conservar y restaurar el conjunto de bienes muebles con valor cultural presentes en el inmueble.

> Proyecto básico y de ejecución de intervención en el inmueble: en apoyo del anterior, para frenar las causas de deterioro que afectaban a la integridad de los bienes muebles y dotar de coherencia al espacio, explicitando la relación entre el edificio y sus bienes muebles que hemos venido en llamar programa iconográfico.

A partir de aquí, en la intervención sobre el inmueble, se plantearon tres líneas de actuación:

> Respecto a la conservación del edificio y sus bienes muebles asociados: se propuso frenar el deterioro en las pinturas murales de la cúpula, que eran el elemento del programa iconográfico más afectado, interviniendo fundamentalmente a nivel de cubiertas. Su estado de conservación era el resultado no sólo de la intervención de los diversos agentes de deterioro que normalmente actúan en un edificio, sino también de deficiencias en su propio diseño.

> Respecto a la adecuación funcional de los espacios: se estudiaron las necesidades actuales que demandaba un edificio tan vivido como éste, donde era necesario compatibilizar las nuevas prestaciones de utilización y seguridad hacia los usuarios con los requisitos de conservación contemplados para los bienes. Es por ello que el edificio debía adecuar sus normas de uso a las condiciones de evacuación en caso de incendio y renovar parte de sus instalaciones.

> Respecto a la puesta en valor y musealización del bien: la importancia como bien cultural de la iglesia requirió considerar como otro factor impor- 


\section{CRONOGRAMA DE ACTUACIONES}

Fase 0. Inicio. Definición de estrategia (octubre 2006-octubre 2009)

Desde la llegada de la petición hasta la formalización del encargo mediante la firma de un convenio de colaboración. Implica la elaboración de un diagnóstico con una propuesta técnica y económica.

2006_11: Redacción de Propuesta técnica y económica. Estudio de viabilidad.

2009 09: Firma del Convenio de Colaboración entre la Consejería de Cultura de la Junta de Andalucía, el Instituto Andaluz del Patrimonio Histórico, la Fundación Montemadrid y el Obispado de la Diócesis de Málaga para la restauración de la iglesia del Santo Cristo de la Salud de Málaga.

2009 10: Encomienda de Gestión de la Consejería de Cultura al IAPH.

Fase 1. Redacción de informes y proyectos que constituyen el Proyecto de Conservación (sep. 2009-marzo 2012)

Desde la formalización del encargo hasta la redacción de la propuesta de intervención. Comprende la realización de diversas actuaciones como la realización de visitas técnicas, seguimiento y coordinación de los equipos, redacción de informes y proyectos y supervisión técnica de los contenidos de los proyectos conforme a la normativa vigente.

2011_05: Redacción de Documento de bases y estrategia.

2011_09: Redacción del Proyecto de Conservación del programa iconográfico de la iglesia del Santo Cristo de la Salud. Comprendiendo los estudios: Levantamiento planimétrico; Estudios de técnicas de examen por imagen; Estudios analíticos; Estudios medioambientales; Estudio histórico; y proyectos: Proyecto de Conservación de los bienes muebles; Proyecto Básico de Intervención en la iglesia del Santo Cristo de la Salud; Proyecto de andamios, instalaciones y medios auxiliares; Estudio de Seguridad y Salud.

2012_03: Redacción del Proyecto Básico y de Ejecución de Intervención en la iglesia del Santo Cristo de la Salud.
2012_03: Redacción del Proyecto de actividad arqueológica de control de los movimientos de tierra en la iglesia.

Fase 2. Tramitación y licitación de obras (mayo 2011-noviembre 2012)

Desde que se redacta el proyecto hasta que comienzan las obras. Comprende la tramitación administrativa de las licencias correspondientes y licitación de la ejecución de las obras. Supone asimismo la revisión del proyecto en función de los informes sectoriales emitidos por las instituciones competentes para garantizar la calidad de la intervención, el consenso entre todos los agentes sociales y la transparencia del procedimiento.

2011_05: Aprobación del Proyecto de Conservación del programa iconográfico de la iglesia del Santo Cristo de la Salud por la Comisión Técnica de Proyectos y Obras según Convenio.

2011 12: Informe positivo de la Comisión Provincial de Patrimonio Histórico de Málaga al Proyecto de Conservación del programa iconográfico de la iglesia del Santo Cristo de la Salud.

2012 09:Autorización de la Delegación Territorial de Educación, Cultura y Deporte de Málaga al Proyecto de actividad arqueológica de control de los movimientos de tierra en la iglesia.

2012_10: Autorización de la Delegación Territorial de Educación, Cultura y Deporte de Málaga al Proyecto Básico y de Ejecución de Intervención en el inmueble.

2012 11: Concesión de Licencia de obras al Proyecto Básico y de Ejecución de Intervención en el inmueble por parte de la Gerencia Municipal de Urbanismo, Obras e Infraestructuras de Málaga.

\section{Fase 3: Ejecución de las obras (marzo 2013-noviembre 2014)}

Comprende la ejecución de la obra y los trabajos de restauración, lo que implica la realización de numerosas actuaciones relacionadas con la coordinación de los equipos, seguimiento económico del proyecto, realización de visitas de obra y elaboración de la documentación técnica asociada (actas, certificados e informes).
2012 03: Puesta a disposición del edificio para el inicio de los trabajos.

2012_10: Traslado de 27 bienes muebles a los talleres del IAPH en Sevilla. Inicio del proceso de restauración.

2013_06: Inicio de las obras en el inmueble con la empresa BAUEN Constructora S. A. Acta de comprobación de Replanteo e Inicio de Obra. Acta de comprobación de montaje de andamios. Incorporación del equipo de restauradores del Instituto Andaluz del Patrimonio Histórico para inicio del proceso de restauración in situ.

2014_05: Solicitud de Modificado de Proyecto.

2014 06: Autorización de redacción de Modificado.

2014_07: Informe de Propuesta de Modificado a la Comisión Provincial de Patrimonio Histórico de Málaga. Redacción de Modificado de Proyecto.

2014_09: Informe de Supervisión del Modificado favorable. Acta de replanteo del Proyecto.

2014_11: Autorización de la Delegación Territorial de Educación, Cultura y Deporte de Málaga al Modificado de Proyecto.

\section{Fase 4: Finalización de las obras} (noviembre 2014-julio 2015)

Desde la finalización de las obras hasta la recepción de edificio por parte del usuario.

2014_11: Finalización de las obras.

2014_12: Ejecución de repasos. Notificación al promotor de obra acabada. Certificado final de obra.

2015 03: Acta de recepción de edificio terminado.

2015_04: Liquidación de obra.

2015_06: Memoria final de la intervención. Libro del edificio.

2015_07: Recepción del edificio por parte del Obispado de Málaga. 
Ámbito de intervención | plano Fondo Gráfico IAPH (redactores del Proyecto de Intervención en el Inmueble), para todos los planos del artículo salvo que se especifique lo contrario

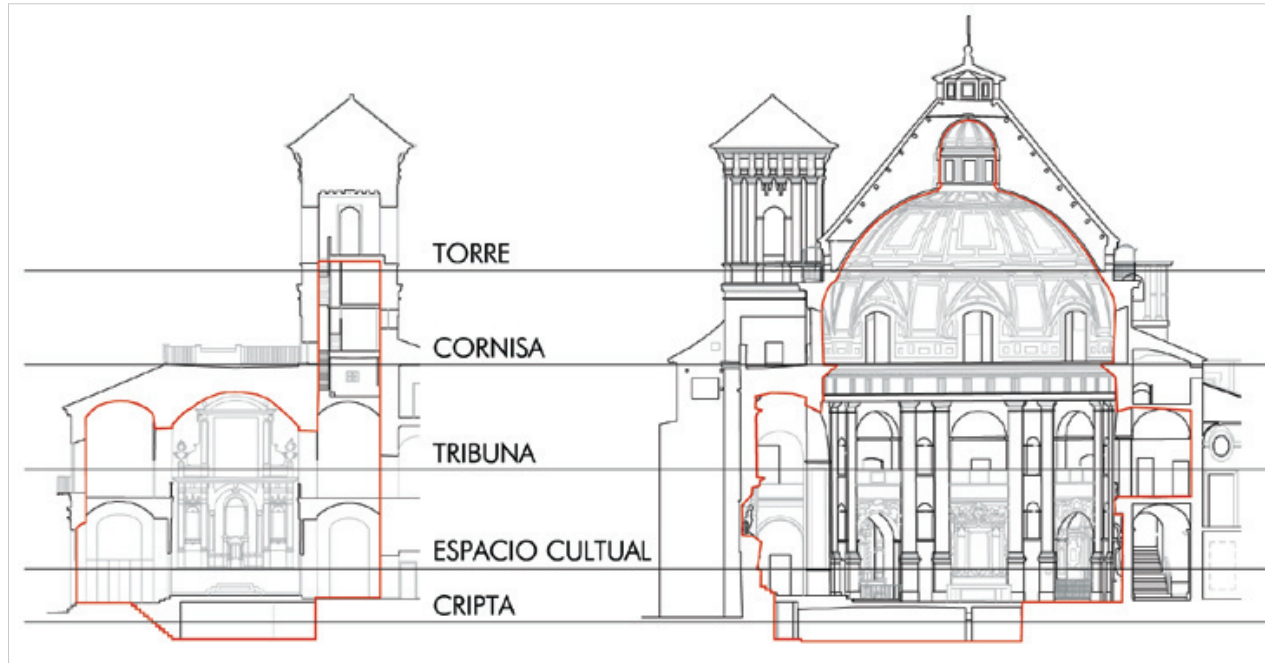

tante las visitas culturales, por lo que la propuesta incorporó actuaciones a nivel de museología y museografía, por medio de la reordenación espacial del presbiterio y capillas y un nuevo sistema de iluminación en el interior.

Para ello los estudios previos (levantamiento planimétrico, estudios de técnicas de examen por imagen, analíticos, medioambiental e histórico) se orientaron a identificar los factores de deterioro para: frenar las causas; identificar, datar y valorar algunos elementos muebles para justificar la reordenación del programa iconográfico; evaluar el comportamiento de algunos elementos constructivos del edificio para ver la viabilidad de su sustitución o mejora; y definir los valores espaciales y funcionales de los distintos ámbitos de intervención para revisar las nuevas condiciones de uso.

En definitiva, las actuaciones propuestas y ejecutadas en el siglo XXI han venido determinadas por un balance entre el valor cultural del bien, su estado de conservación y las condiciones de uso y disfrute de los usuarios.

\section{Los trabajos previos}

La intervención en el edificio se planificó a partir de un cronograma de actuaciones conjunto entre el equipo de intervención en el inmueble y el equipo de restauradores de bienes muebles donde, a modo de referencia, se preveía la secuencia y duración estimada de todos los trabajos para no coincidir en el tiempo en un mismo ámbito de intervención y poder compartir los medios auxiliares, entre ellos y con el público del programa de visitas. Por parte de ambos equipos existían dos condicionantes importantes: que muchas de las actuaciones en el interior de la iglesia no se podían superponer, sólo podían ser encadenadas; y que el plazo de ejecución del equipo de bienes muebles 


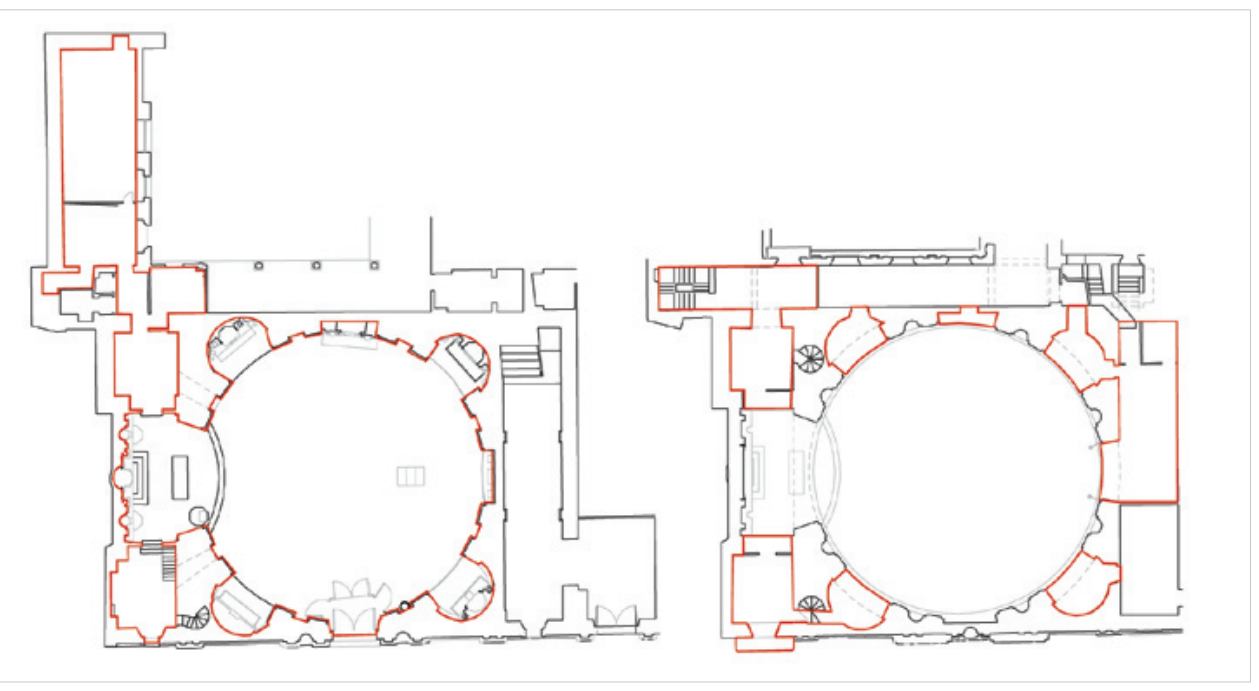

era improrrogable. Siendo conscientes de que nuestro proyecto iba en apoyo de los bienes muebles, el criterio general a seguir fue frenar las causas de deterioro antes de que ellos paliaran sus efectos, y establecer sistemáticamente visitas conjuntas en obra para coordinar los inevitables imprevistos. Antes de la recepción del edificio por parte del IAPH, se realizó un inventario de bienes culturales y cultuales en base al cual determinar -especialmentelos que no volverían a la iglesia tras la intervención, para ser retirados por sus propietarios antes del inicio de los trabajos.

Una vez entregado el edificio por el obispado, se llevaron a cabo una serie de actuaciones previas en el interior de la iglesia necesarias para la implantación de la obra:

$>$ el desmontaje y retirada definitiva de la señalética obsoleta y demás elementos sin interés cultural;

$>$ la limpieza y acondicionamiento de los espacios servidores de la iglesia como almacén de productos de restauración, taller provisional de restauración de bienes muebles y despachos para los dos equipos de trabajo;

$>$ la protección previa de las capillas a la espera de ser restauradas, con un tejido transpirable para absorber las partículas de polvo generadas en esta fase por el equipo de obra;

$>$ el montaje de un andamio modular multidireccional de cuatro niveles de plataforma en el presbiterio, para permitir una zona de trabajo independiente al equipo de restauración del IAPH en el retablo mayor, los paramentos y las tribunas del presbiterio mientras la empresa constructora actuaba en el ámbito de la nave; $y$

$>$ el levantado de la mayor parte de la solería de la nave con objeto de construir la solera ventilada sobre la que apoyara el andamio central. 


\section{EL PROCESO DE INTERVENCIÓN}

\section{Mejorando la conservación del edificio desde la cubierta}

A partir de aquí las primeras actuaciones se centraron en la cubierta, donde era prioritario intervenir para frenar la entrada de agua en la cúpula antes de la llegada del período de lluvia y de que los restauradores intervinieran en las pinturas murales.

Las actuaciones en el exterior comenzaron con el montaje del andamio de fachada, previsto en toda su altura para su limpieza y restauración así como medio para subir los acopios a cubierta desde el exterior. No se levantó desde un principio en toda su longitud, sino sólo el tramo que contaba con elevador en la parte más ancha de la vía, para no dificultar en ese período la salida de los restos de la anterior solería de la iglesia.

Los trabajos en la cubierta se centraron en la eliminación de las humedades de infiltración a través de la galería perimetral y la mejora de las condiciones de ventilación de la cámara bajo cubierta.

En primer lugar se acometió la limpieza de los faldones de cubierta y se picó una zona del zuncho perimetral para conocer la naturaleza y alcance de la grieta presente en toda su longitud. Tras constatar que la grieta era estable, y se debía a la diferencia de coeficientes de dilatación entre el ala de acero del perfil y su revestimiento en hormigón, se colocó un elemento flexible en este punto: una malla de refuerzo de fibra de vidrio en la superficie y un revestimiento con mortero de cal, que se entonó con los paramentos de la galería perimetral cuando se finalizaron y se comprobó la imagen general junto a la fachada desde la plaza.

Siendo la galería perimetral el punto de la sección del edificio más vulnerable a la entrada de agua, por cuestiones de diseño y falta de mantenimiento, se comenzó levantando el suelo existente y se descubrió que bajo éste se encontraba la baldosa cerámica original, aunque en un estado de conservación incompatible con los requerimientos de aislamiento e impermeabilización necesarios. No obstante, se documentó este registro y se adoptó ese formato y despiece para la nueva solería. Se ejecutó una nueva formación de pendiente en mortero de cal con un recrecido de $4 \mathrm{~cm}$ en el interior para mejorar la evacuación de pluviales y se ejecutó la nueva impermeabilización mediante lámina de PVC, ejecutando una zabaleta en el encuentro con el paramento para evitar nuevos puntos de entrada de agua. Buscando la continuidad de dicha lámina hacia el exterior, se vio inviable hacerla pasar por debajo de los soportes originales de piedra de las barandillas, teniendo que pasar por encima. Esta última decisión por cuestiones de conservación nos supuso reflexionar sobre la manera de proteger la lámina en este punto 
sin distorsionar el valor cultural de estas piezas y la solución que se decidió más limpia y reversible fue la de ejecutar unas carcasas en acero inoxidable que recordaran su volumetría y se integraran con el tono de las chapas de cobre envejecidas de las cornisas. Finalmente se soló la galería, disponiendo en el borde libre baldosas cerámicas con goterón superpuestas a un gran alero de chapa de cobre para evitar el chorreo bajo esta galería a través de la cornisa.

En el mismo sentido se tuvo que actuar sobre los paramentos para evitar la entrada de agua y las migraciones de sales. Por lo que se eliminaron los morteros de cemento y otros en mal estado que se localizaban fundamentalmente en la parte baja, las sales procedentes del zuncho mediante papetas con pulpa de papel y agua destilada y, por su carácter hidrófugo, los revestimientos de yeso que estaban disgregados. Estas primeras actuaciones pusieron en evidencia la presencia en las esquinas de grandes bloques de piedra que habían quedado ocultos bajo los revestimientos. La mera remoción del mortero superpuesto no era suficiente como acabado, sino que el nivel de detalle llegó al grado de tener que definir cómo resolver el encuentro entre estos bloques de piedra y el resto del paramento de ladrillo con el mortero de restauración para que no diera la sensación de un aplacado.

Asimismo, y de manera generalizada, se realizó una limpieza por medio de un cepillado con jabón neutro, se rejuntó con mortero de cal, se sellaron grietas y fisuras, se repusieron ladrillos arenizados y se hidrofugaron todas las superficies. En los huecos de las celosías se realizó un nuevo recercado con mortero de cal y un nuevo alféizar con baldosas cerámicas macizas.

De manera complementaria se sustituyeron las celosías de madera por otras en acero galvanizado en un tono marrón rojizo (como los paramentos, las carcasas de los soportes de las barandillas y las cornisas de cobre) para mejorar su durabilidad y garantizar la ventilación continua de la cámara de cubierta. En ésta las actuaciones tuvieron como finalidad principal mejorar la ventilación de la cámara entre la cubierta y la cúpula sin modificar su equilibrio higrotérmico. Para facilitar el mantenimiento se dotó de iluminación de servicio, se repasó la escalera de subida a la linterna, se repuso el entarimado de madera en la linterna de la cubierta, se ejecutaron dos líneas de vida y se mantuvo como definitiva la solución de perfiles tubulares soldados a las prótesis metálicas de la vigas para el cuelgue de plataformas de registro, por su utilidad y mínima sobrecarga aplicada a la estructura.

También se intervino a efectos de conservación sobre la estructura de la cubierta, aplicando tratamientos antixilófagos en las vigas de madera, protegiendo de la oxidación las prótesis metálicas y pasivando los paneles de nervometal de los faldones con mortero puzolánico. 
PROCESO DE INTERVENCIÓN EN EL EXTERIOR
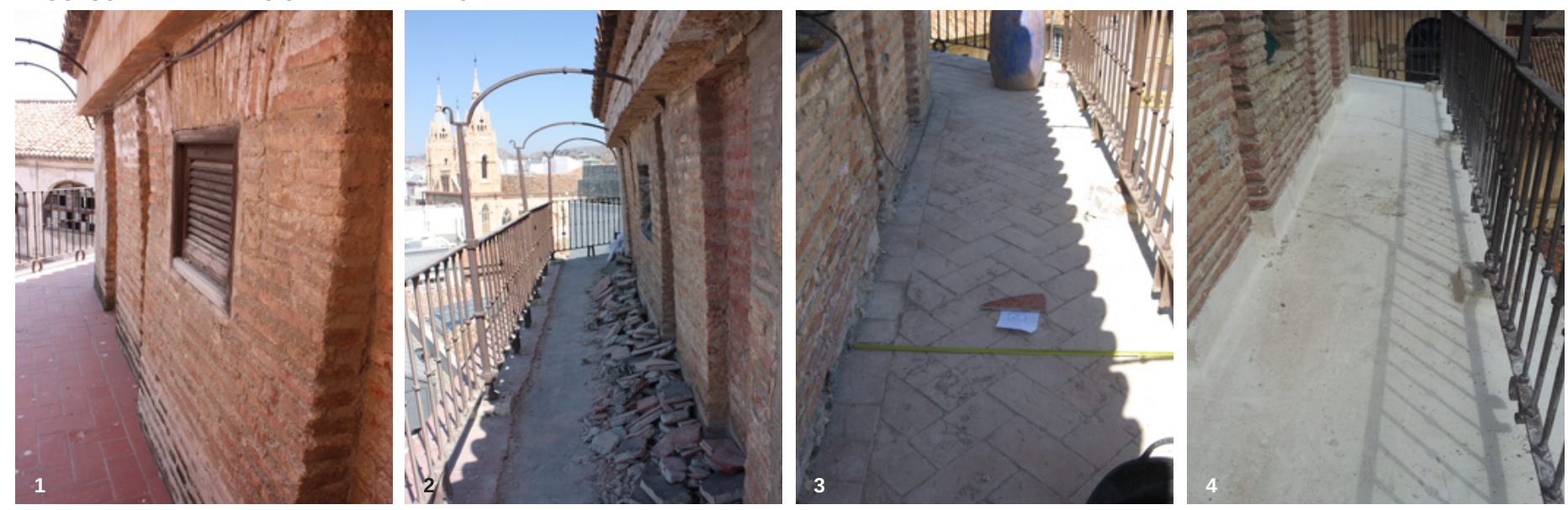

Conservación de la cubierta | fotos Fondo Gráfico IAPH (Aurora Villalobos Gómez: 1, 6, 7, 8; Javier Hijano Fernández: 2, 3, 4, 5)
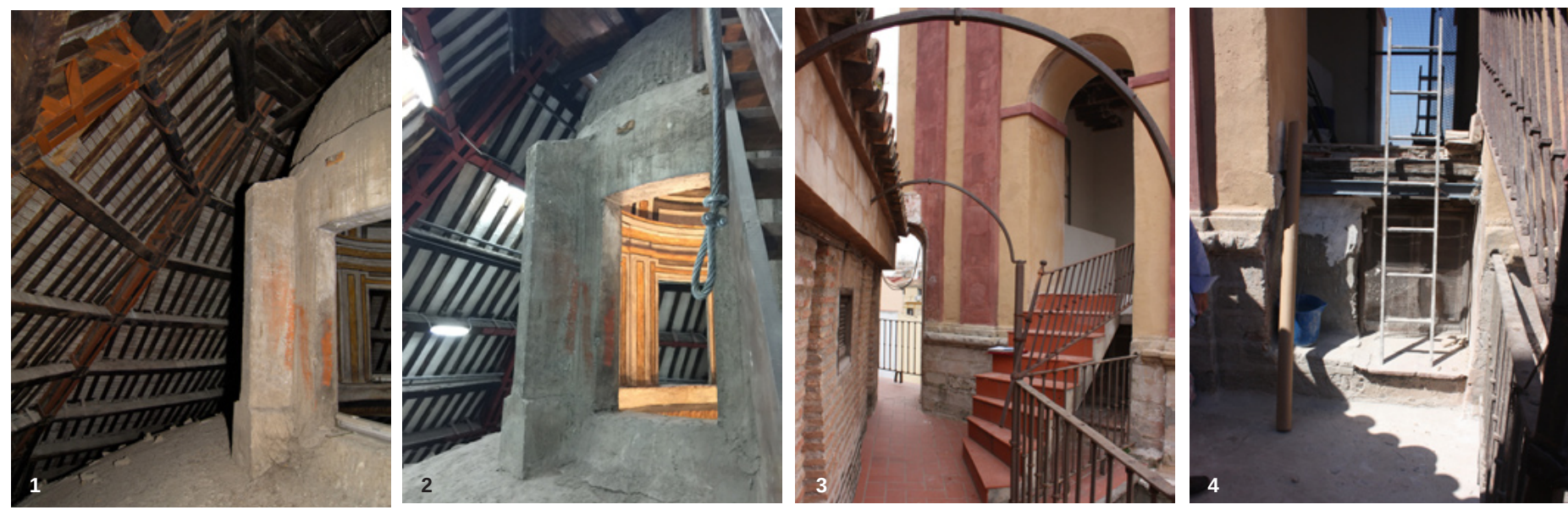

Mejoras para el mantenimiento | fotos Fondo Gráfico IAPH (J. M. Santos Madrid: 1, 3; A. Villalobos Gómez: 2, 4, 5, 7, 8; Ana Bouzas Abad: 6)
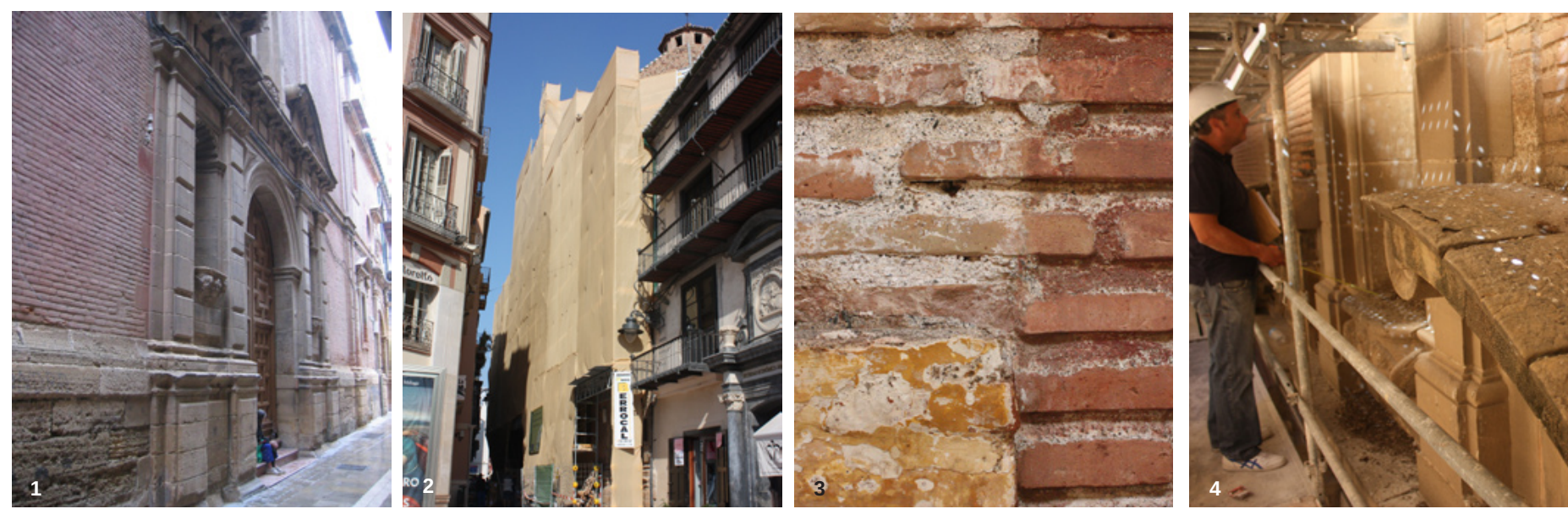

Actuaciones en fachada | fotos Fondo Gráfico IAPH (Aurora Villalobos Gómez) 

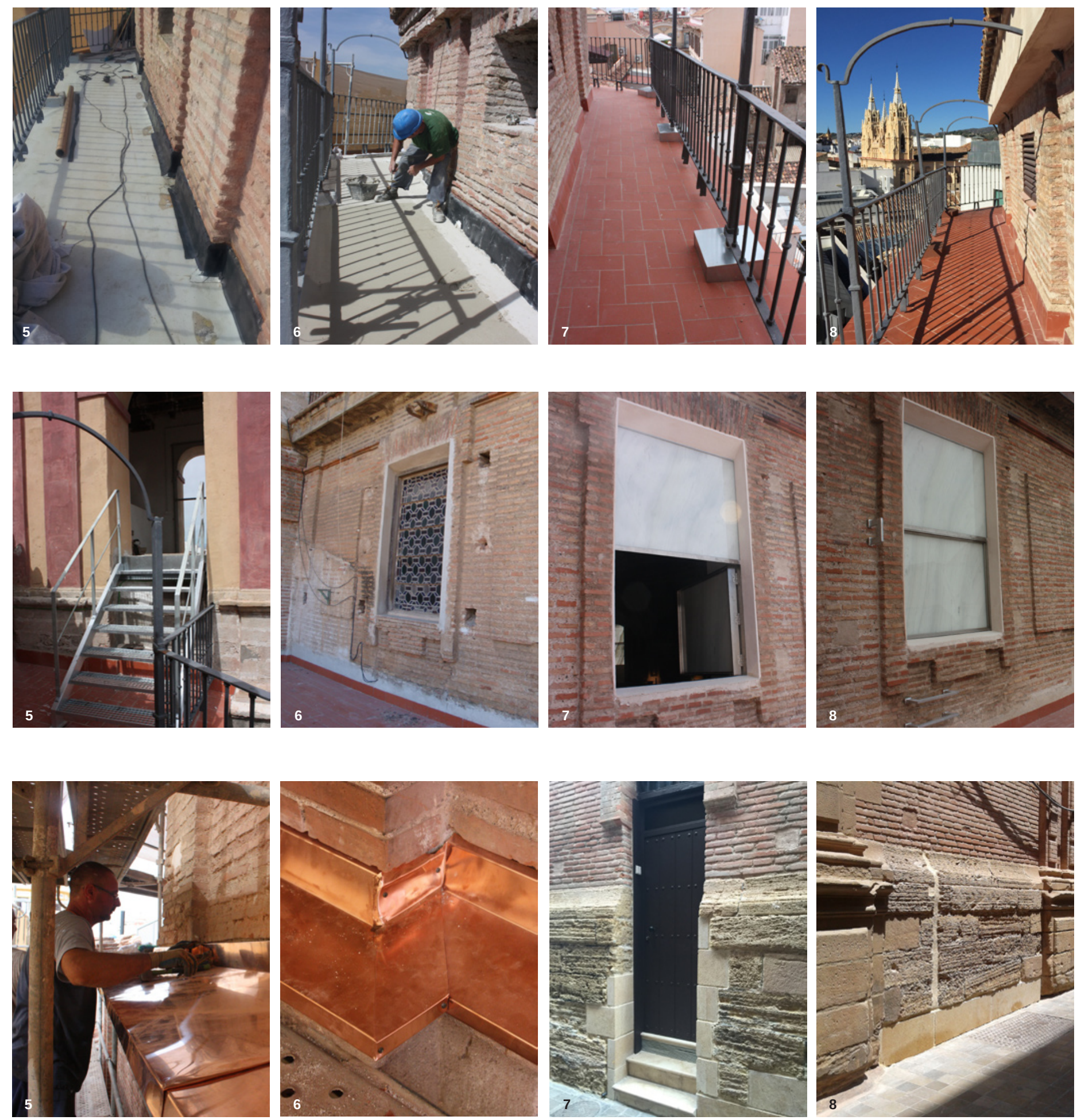


\section{Devolviendo la presencia urbana a la fachada}

En paralelo a los trabajos en cubierta y una vez finalizadas las actuaciones previas en el interior de la nave, pudo montarse el otro tramo de andamio y comenzar las actuaciones en la fachada, con el propósito de mejorar sus condiciones de conservación, minorar el riesgo de deterioro en las zonas más expuestas y recuperar una imagen integral, a pesar de las dificultades de percepción en toda su altura en un tramo de calle tan estrecho.

Se comenzó realizando la limpieza, aplicación de biocida e hidrofugación general de la fachada, por este orden, desde la derecha hacia la izquierda y desde arriba hacia abajo. La dirección de obra insistió mucho en el criterio de profundidad de la limpieza, para que se eliminaran los depósitos de polvo sin llegar a la superficie limpia del ladrillo, para no perder la sutil información cromática que se desvelaba en este proceso. Es por eso que se limpió la fachada con un jabón neutro y, en caso de presencia de sales y eflorescencias, se realizó con un cepillo en seco. Comenzaron entonces a desvelarse entre los paños rojizos, apilastrados de ladrillo en color ocre y falsos marmoreados en la portada de piedra del acceso principal. En algunos casos tuvieron que aplicarse en algunas zonas jabelgas muy diluidas para igualar los tonos e incluso retirar algunos revestimientos de color posteriores que distorsionaban la lectura global de la fachada. Estos trabajos no sólo dieron a conocer que los colores usados eran semejantes a los hallados en el tambor de la cúpula (ocre en las pilastras y rojo en los paramentos) sino que pusieron en relación visual dos elementos que hasta ahora se percibían inconexos.

Las actuaciones en fachada se fueron ejecutando de manera ordenada y sistemática, si bien la heterogeneidad de su estado de conservación y la diversidad de trabajos requirieron de una revisión permanente y detallada por zonas de los métodos y criterios previstos en proyecto. Aunque el estado de conservación de la fachada no parecía preocupante desde la cota de la calle, el registro desde las diversas plataformas del andamio puso de manifiesto la presencia generalizada de fisuras y descamaciones en la parte superior de los elementos salientes en piedra de la portada, ladrillos arenizados, parcheados con morteros de cemento y numerosos mechinales que requerían una actuación pormenorizada. Tanto es así que sobre los elementos salientes en piedra se aplicó una ligera lechada con una fina capa de mortero de cal para frenar la erosión e impermeabilizarlos de la escorrentía. Además de ejecutar una media caña con mortero de cal para evitar la entrada de agua en el encuentro con el paramento, se repusieron los ladrillos arenizados con otros de igual composición; se eliminaron todos los morteros de cemento por el riesgo de migración de sales, excepto en la última cornisa de la fachada donde estaba tan extendido que eliminarlo hubiera supuesto poner en riesgo la materialidad de este elemento y tener que rein- 
tegrarlo casi en su totalidad, cuando en verdad la chapa de cobre prevista a lo largo de todo el perfil impediría la exposición al agua y por lo tanto el referido riesgo; también se detectaron nuevos mechinales de los que no se quería perder el registro del proceso constructivo pero que no podían permanecer abiertos por el anidamiento de aves y la acumulación de suciedad, por lo que se taponaron con una pieza cerámica, se revistieron en sucesivas finas capas de mortero de cal, quedando retranqueados $1 \mathrm{~cm}$ aproximadamente y se entonaron con un tono parecido al de las juntas de los morteros originales en los paños rojizos de ladrillo. Han sido también varias las actuaciones puntuales que han ido surgiendo a demanda de la propia obra: restauración a fondo del escudo de la portada del Ateneo de Málaga, reposición del solado del balcón de la tribuna $\mathrm{S}$ del presbiterio, cosido del dintel de una ventana del Ateneo, etc.

De especial interés fue el revestido de las cornisas principales de fachada con chapa de cobre de $0.6 \mathrm{~mm}$ de espesor y goterón recto para protegerlas de la erosión, evitar el efecto de delavado en los paramentos y la aparición de cianobaterias. Se bajó el espesor previsto en proyecto para facilitar los pliegues del material y, por cuestiones de suministro, se recurrió a una chapa comercial de $50 \mathrm{~cm}$ de anchura que se engatilló en la cornisa superior de la fachada para conseguir un mayor descuelgue. Al poco tiempo se encontraba completamente integrada con los tonos rojizos de la fachada.

Otra cuestión que afectaba a la imagen general de la fachada y supuso una exhaustiva búsqueda del material y la ejecución de numerosas muestras de acabados superficiales, morteros y juntas fue la reintegración del zócalo de piedra de la fachada. Se trataba de un zócalo de 1,8 metros de altura y 18,5 metros de longitud, constituido por seis hiladas de sillares de piedra caliza (como la Catedral de Málaga) con injertos de esquirlas de pizarra en las juntas. Su función era la de proteger los paramentos de la humedad de capilaridad, ofreciendo una superficie porosa a modo de esponja que, con la misma facilidad con la que absorbe el agua, la eliminara. Sin embargo, se encontraba muy deteriorado a causa de las escorrentías de agua de la calle y el efecto de salpicadura de las cubiertas.

La intervención consistió en la limpieza, consolidación, resanado de juntas, sellado de grietas y sustitución de los sillares en mal estado con una piedra similar a la original en dimensión y material. Las zonas más afectadas eran la primera hilada en contacto con el pavimento de la calle así como las jambas del acceso secundario. Como criterio general, se decidió colocar las nuevas piezas en un segundo plano levemente retranqueado respecto a la línea de fachada, para generar una franja de sombra que diluyera el corte entre ambos tramos, en una operación análoga a la reintegración arqueológica de lagunas murales. Para ello se localizó el mismo litotipo en color nogal y se suministraron piezas de igual longitud a las existentes pero de 10 
$\mathrm{cm}$ de profundidad. Si bien se mostraron diversas muestras de abujardado, el tono de la piedra era tan similar que no se concebía debilitar expresamente el material por una cuestión estética, a riesgo de generar un falso histórico, por lo que se decidió presentarla con el corte de sierra contando con que el paso del tiempo y la acción de los agentes meteorológicos los irá igualando. Mientras que en estas piezas se optó por juntas rehundidas con mortero de cal con acabado grueso en color ocre, la fábrica histórica se rejuntó con un tono blanquecino similar al mortero original. En ambos casos se incorporaron áridos oscuros libres de sales, en analogía con las lascas de pizarra. De acuerdo con los criterios generales consensuados en patrimonio, con esta actuación de carácter conservativo se han garantizado la compatibilidad de materiales, su integración visual y la discernibilidad de las reintegraciones.

Desmontando el andamio de fachada, se pudo comprobar que el nivel de limpieza había sido homogéneo al no detectarse tonos disonantes en los paramentos y que las múltiples intervenciones puntuales se habían integrado en el conjunto, dando la impresión de que siempre hubiera estado así.

\section{Descubriendo un espacio interior ordenado y luminoso}

Los trabajos en el interior se centraron en la clarificación espacial del espacio cultual para enfatizar la reordenación del programa iconográfico y la actualización de las instalaciones para mejorar las prestaciones a los usuarios. Las actuaciones resultaron más delicadas y complejas de gestionar dado el excepcional valor patrimonial del espacio cultual y la coexistencia de los dos equipos de trabajo y el programa de visitas.

De acuerdo con el equipo de restauración de los bienes muebles, se consideró que el equipo de intervención en el inmueble debía entrar en primer lugar en la nave de la iglesia parar retirar la solería, excavar la zanja perimetral de instalaciones y ejecutar la solera ventilada sobre la que apoyaría todo el sistema de andamios. A partir de aquí ellos podrían incorporarse a este ámbito. Mientras tanto podían intervenir en el presbiterio o capilla mayor, donde se acondicionó un andamio para la reparación de la bóveda, la restauración del retablo mayor, la limpieza de las dobles barandas de las tribunas y la recuperación de unas pinturas murales en los paramentos laterales. No se esperaba que éstas se encontraran en tan buen estado de conservación ni que fueran de una calidad tan excepcional, imitando el ónice de la mesa del altar original (trasladada a la base del retablo tras el Concilio Vaticano II). Tal circunstancia puso en crisis la solución prevista en este espacio de un rodapié en mármol crema sobre un paramento enfoscado en blanco y el diseño definitivo no pudo definirse hasta el final de la obra tras tener una visión de conjunto. Lo que no estaba previsto en estos trabajos de restauración fue descubrir unas pinturas murales con figuras y el emblema de la Compañía 
de Jesús en el intradós del arco de comunicación de la tribuna $\mathrm{N}$ al demoler las particiones de las tribunas al presbiterio, en el espacio que se apuntaba desde el estudio histórico como capilla doméstica del colegio-noviciado.

Una vez que el equipo de restauradores pudo pasar a la nave, lo primero que hicieron fue desmontar el altar en el hueco $\mathrm{N}$, al tratarse de un espacio que históricamente nunca había estado destinado para el culto. Fue entonces cuando se descubrió el antiguo hueco de paso al noviciado, cuya posición se intuía pero del que no se tenía constancia material. La conexión con el patio del noviciado era un elemento de interés desde el planteamiento inicial del proyecto. El descubrimiento del arco, la puerta y los umbrales de paso originales, en dimensiones inferiores a las previstas, nos hicieron descartar la solución traslúcida planteada en proyecto. Resultando inviable la recuperación de la conexión física, se ha dejado finalmente a la vista lo descubierto para que de una manera inmediata e intuitiva se lea el hueco, en correspondencia con el cancel de la puerta en el eje transversal.

En esta primera fase, también tuvo lugar el seguimiento arqueológico de los movimientos de tierra en la nave, debidos a la ejecución de la zanja perimetral de instalaciones y la solera. Se localizó la zarpa de los muros y se encontraron unos arcos en el eje de las capillas, asociados a antiguas criptas. Sin embargo, no aparecieron restos de otras solerías históricas, más allá de algunos fragmentos de baldosa cerámica, ya que el subsuelo parecía estar muy removido de intervenciones anteriores. Además, durante el levantado de solería en la zona $\mathrm{S}$ de la nave apareció imprevistamente una solera de hormigón en masa que se decidió eliminar porque impedía la ejecución de la solera ventilada y hubiera modificado la cota del pavimento. Acondicionada la zanja con el nuevo cableado eléctrico, se procedió a ejecutar la solera ventilada conforme a proyecto. Sin embargo, al replantear la cota del pavimento se detectó que sobre el columbario no había altura suficiente para disponer las piezas de ventilación, por lo que se decidió colocar grava de tamaño medio fino a fin de regularizar los niveles y disponer atravesados los tubos de ventilación de PVC de $5 \mathrm{~cm}$ de diámetro para conectar las dos cámaras.

Una vez resuelta esta situación, se pudieron montar los andamios perimetrales a los paramentos de la nave que sirvieron al equipo de bienes muebles para la restauración del frente de las capillas y la recuperación de las pinturas murales ocultas en los capiteles de las pilastras y el friso del entablamento; y al equipo de obra, para proseguir las actuaciones de picado, restituciones volumétricas con mortero de cal, enfoscado con mortero de cal y acabado general con pintura de cal al silicato en los paramentos de la nave sin pintura mural. En las basas y parte baja del zócalo de las pilastras se decidió posteriormente aplicar un enfoscado a base de aquaplast, con un acabado más fino.
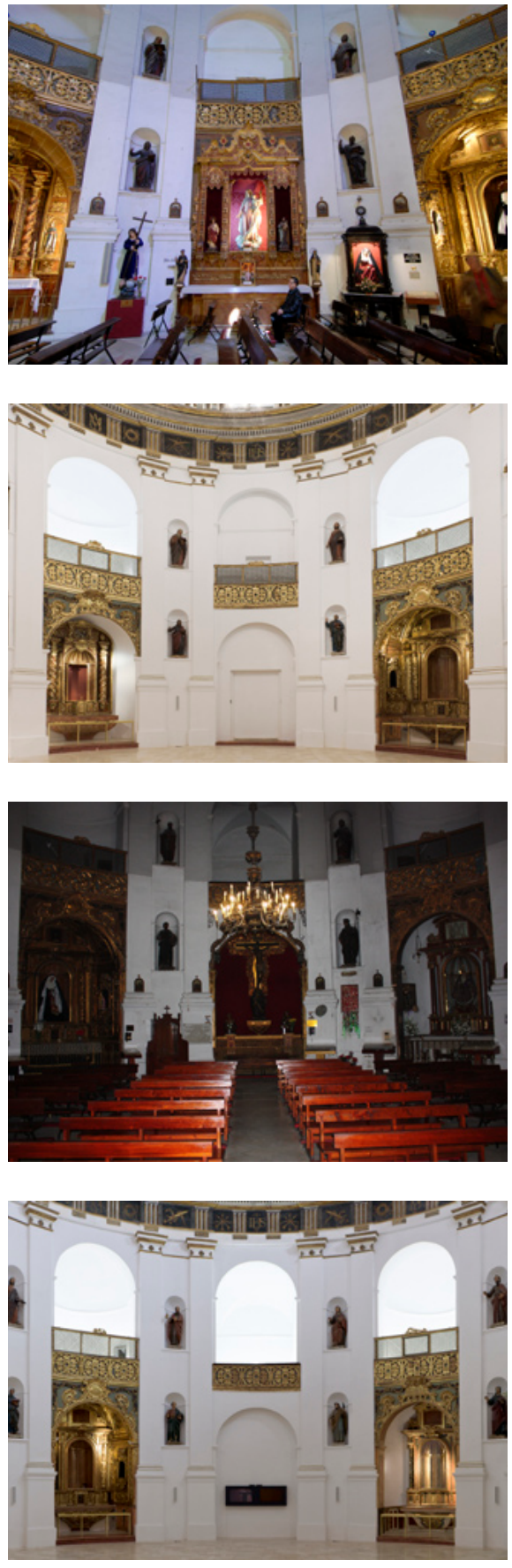

Reordenación del programa iconográfico | fotos Fondo Gráfico IAPH (José Manuel Santos Madrid) 

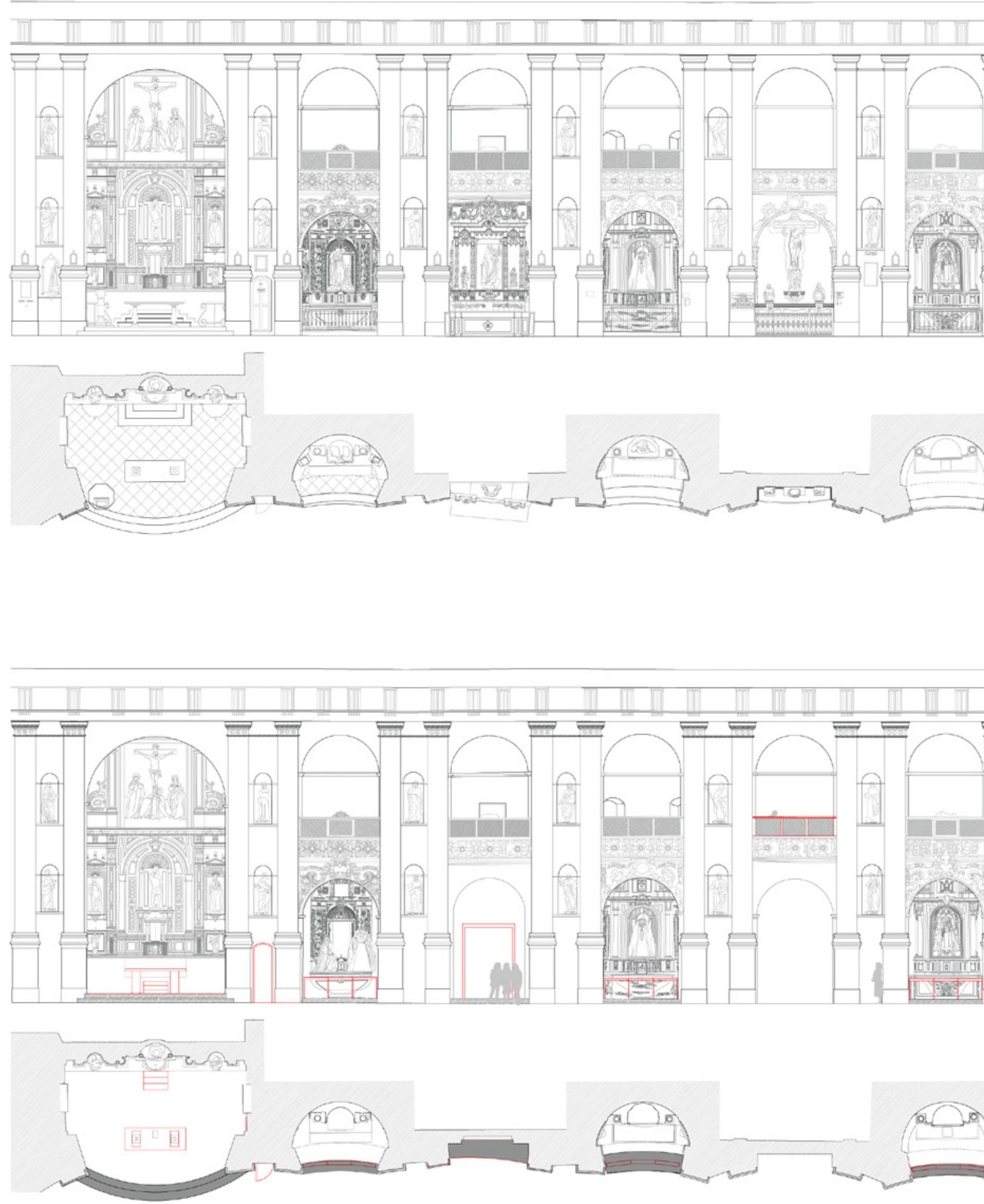

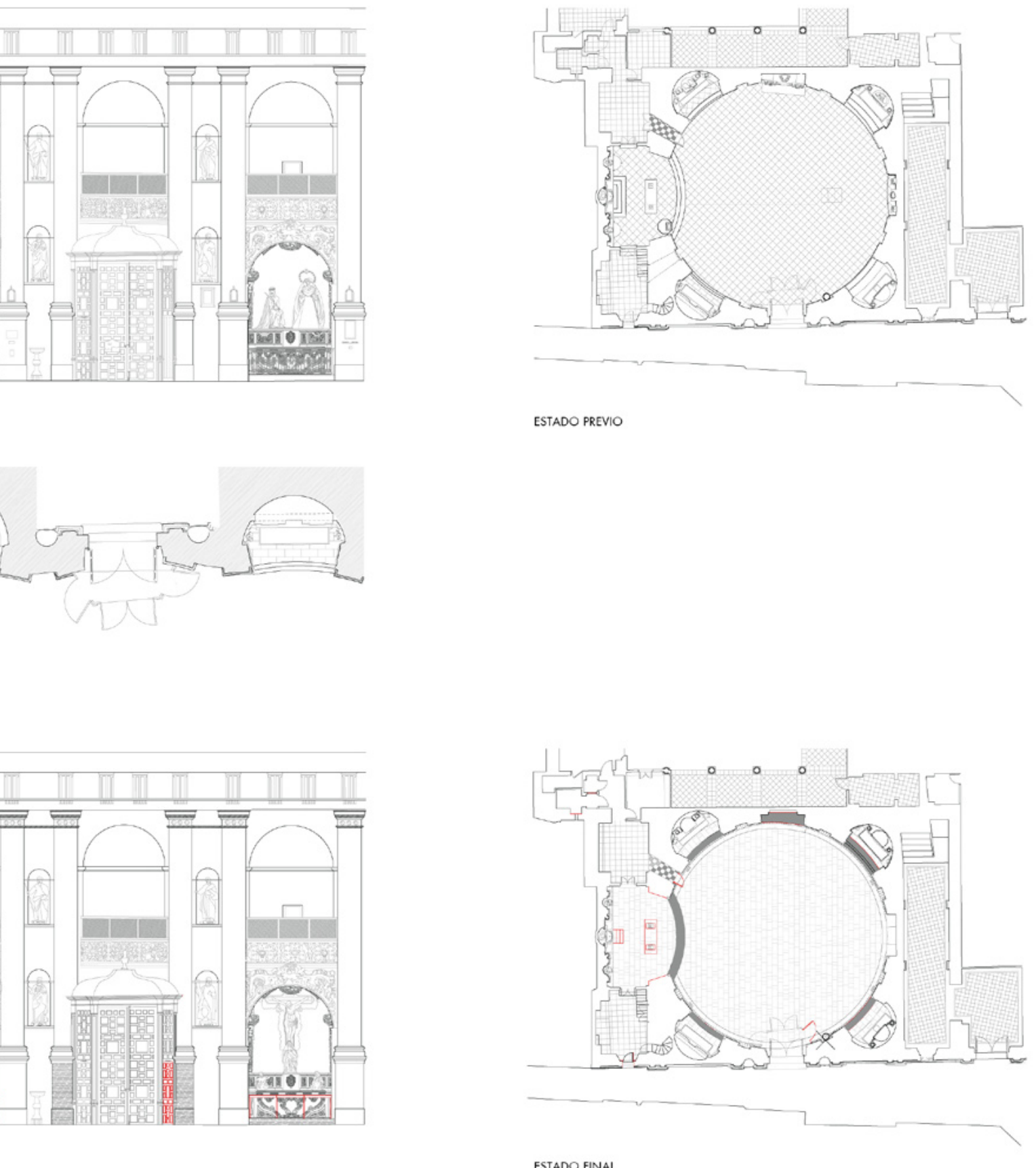

ESTADO FINAL 


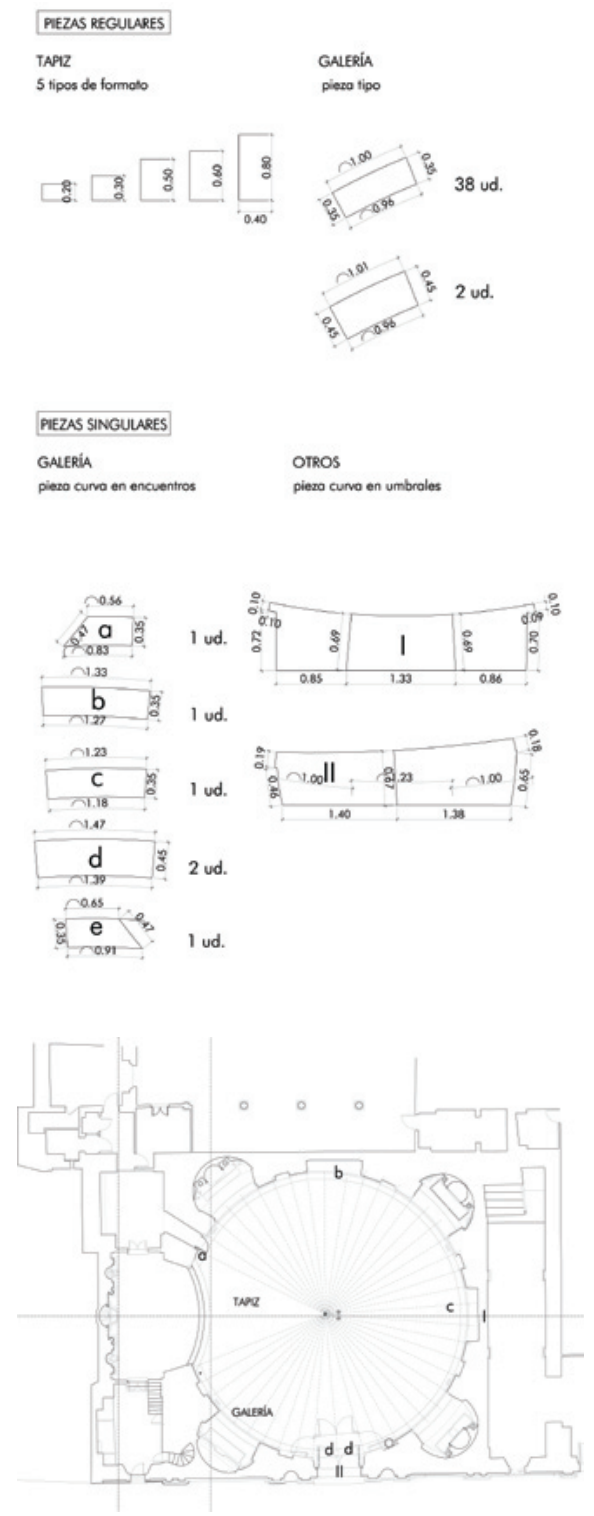

Replanteo y despiece del pavimento
Uno de los objetivos del proyecto de intervención era mejorar las condiciones de iluminación y ventilación de la nave de la iglesia. Montado el andamio central, se pudo acometer la instalación de las nuevas luminarias sobre la cornisa y la sustitución de las vidrieras.

Respecto a la iluminación artificial, la instalación era obsoleta, precaria en mantenimiento e insuficiente en sus prestaciones por lo que los focos de fluorescentes se sustituyeron por proyectores halógenos con filtro UV sobre raíles, ajustables en posición e intensidad a los diversos escenarios de iluminación planteados para activarse de manera conjunta o independiente.

En la nave, se concentraron en la cornisa para iluminar: la linterna de la cúpula, la cúpula con pinturas murales, los paramentos ( $y$, por ende el frente de las capillas y las esculturas en las hornacinas) y el suelo de la nave; y en el presbiterio se concentraron en la mocheta del arco de embocadura con la nave para iluminar: el retablo mayor, el manifestador, el Santo Cristo de la Salud, la tabla de ónice de la mesa de altar original, el suelo, la mesa, el ambón y el atril. Además se introdujeron luminarias de refuerzo en las capillas y tribunas.

Respecto a la iluminación natural, las vidrieras anteriores sobre carpintería de madera no eran las originales, se encontraban en un mal estado de conservación y, sobre todo, distorsionaban la claridad espacial de la cúpula y la percepción cromática de las pinturas murales. Es por ello que se decidió sustituirlas por una novedosa solución traslúcida en dos hojas, desplazadas entre sí para permitir la salida del aire caliente ascendiente e impedir la entrada de agua, y formadas por una lámina de mármol blanco de Macael hacia el interior y un doble vidrio de seguridad extra claro hacia el exterior, sobre carpintería de acero inoxidable mate.

Fue un proceso complejo llevarlas del papel a la realidad: el equipo del proyecto se desplazó a las canteras de Macael (Almería) para seleccionar el bloque de mármol del que se extrajeran las tablas de vidrieras. Se buscaba un mármol blanco con vetas en tonos grises y dorados, en consonancia con el fondo y las molduras de la arquitectura fingida de la cúpula, respectivamente.

Una vez localizado y extraído el bloque se procedió al corte de las tablas, de $2,00 \times 1,30 \mathrm{~m}$ de tamaño aproximadamente y $5 \mathrm{~mm}$ de espesor. A continuació, era necesario adherir las láminas de vidrio con butiral sin que rompiera la lámina de mármol; dadas sus grandes dimensiones y reducido espesor, se tuvieron que cortar previamente las tablas de piedra en damero, manteniendo la continuidad del dibujo de las vetas. El resultado da la sensación visual, incluso de cerca, de que se trata de una sola pieza. Ni que decir tiene las delicadas condiciones de transporte hasta Málaga, de acopio en obra, de 


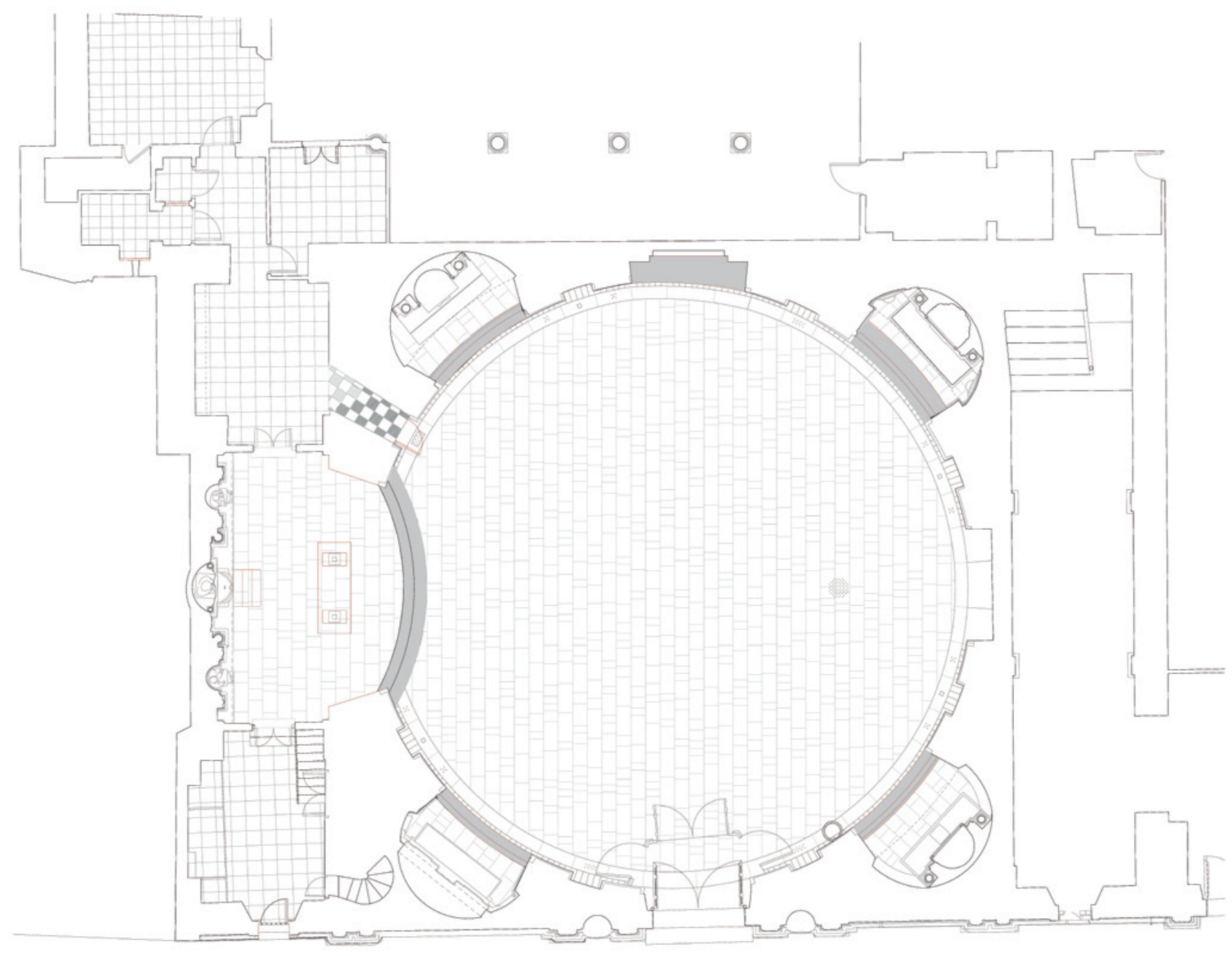

Planta baja. Estado final

subida a la plataforma superior del andamio y de colocación por medio de ventosas. Con este diseño de vidriera se han mejorado las condiciones de conservación -evitándose la humedad de condensación de las pinturas- y de musealización en la nave de la iglesia -aportando un tono de luz claro, tamizado y neutro-. La nueva solución de "vidriera" es contemporánea, durable, resistente al ambiente marino y de fácil mantenimiento.

Mientras el andamio central estuvo montado no se pudo ejecutar la nueva solería de la nave, pero sí la de las capillas. Se planteó la viabilidad de recuperar las tabicas en color para que se comprendiera la tridimensionalidad de este elemento, como así sucedió. 
Una vez que finalizaron los trabajos de restauración de las pinturas murales y que se instalaron las nuevas vidrieras, se pudo desmontar el andamio central para abordar el solado de la nave y más tarde del presbiterio. La solución de solería ejecutada ha sido consecuencia de los nuevos datos respecto al estado de conservación del edificio durante las obras y las dificultades técnicas surgidas con el despiece en piedra a la escala del detalle constructivo. Esta actuación estaba justificada ante la inexistencia de cualquier resto de suelo subyacente y ausencia de criterio patrimonial en los sucesivos solados de la nave con piezas de mármol blanco de 40 x 40 y del presbiterio en damero blanco y rojo.

No existiendo referencia documental ni constancia material de un despiece concreto del pavimento original, se acordó con la Comisión de patrimonio un nuevo pavimento contemporáneo a modo de elemento neutro en la nave de la iglesia, presbiterio y capillas. Para ello se proyectó en la nave circular una superficie continua (tapiz), remarcada por un anillo perimetral (galería). Dicho tapiz presentaba un despiece reticular en mármol de color crema, con las juntas a hueso y tomando como base un formato de $40 \times 80 \mathrm{~cm}$, presentado en diversos cortes.

De este modo, sin fijar una imagen definitiva de pavimento con un despiece normalizado o un tamaño fijo de baldosa, el tapiz sugiere sutilmente la orientación del culto hacia el presbiterio, cualifica el eje calle-patio y permite una cómoda disposición del mobiliario sobre la planta. De manera complementaria, el anillo perimetral que oculta la nueva galería técnica de instalaciones sugiere la sombra de la cornisa circular de la iglesia y genera un área de respeto frente a los paramentos decorados con pintura mural. Se escogió en fábrica un bloque de mármol crema con ligeras vetas doradas para incorporar un plano de color suave que aportara calidez a la iglesia y fuera compatible con los umbrales históricos de mármol rojo en el presbiterio, capillas y antiguo paso al patio del noviciado.

Las posibles dificultades técnicas durante la ejecución se solventaron a partir del diseño. Se optó por baldosas de diverso formato a partir de una pieza base de $40 \times 80 \mathrm{~cm}$ para mejorar su maniobrabilidad durante el proceso de puesta en obra, así como su durabilidad al quedar bien asentadas y no quebrar por fallo en el soporte. También se decidió ejecutar el encuentro entre las piezas curvas del tapiz y el perfil irregular del paramento de la nave con pequeñas piezas rebajadas respecto a la cota del suelo ante la imposibilidad de recuperar un revestimiento de pintura mural en las pilastras de la nave que resultó de baja calidad de ejecución y estado de conservación.

Para el replanteo de las piezas rectangulares del tapiz se tomó como referencia una línea paralela a la pared del presbiterio y para el de las piezas curvas de la galería un punto de la nave a modo de centro de los cuatro arcos de 
circunferencia de los paramentos. Empezaron a colocarse simultáneamente las piezas curvas del perímetro -para construir el rebaje de encuentro con los paramentos- y la hilada de piezas rectangulares tangente al presbiterio. Posteriormente se colocaron las baldosas rectangulares precortadas para construir el encuentro con las baldosas curvas y por último, las piezas singulares, cuyas dimensiones se verificaron in situ con unas plantillas antes de encargarlas definitivamente.

En un tercer tiempo, casi al final de la obra, es cuando se realizó el tratamiento final de acabado apomazado de la solería y se ejecutaron las perforaciones con broca al agua para ventilar la galería de instalaciones y la cripta. El nuevo pavimento se ofrece como una superficie continua neutra que aporta un tono cálido al interior, en correspondencia con los tonos dorados de la arquitectura de la cúpula y las maderas policromadas de los retablos. De este modo, se concluyen las actuaciones en materia de conservación que se propusieron con el fin de aislar la solería del terreno, registrar las instalaciones en una galería perimetral enterrada y ventilar la base de los muros.

Aprobado el Modificado del proyecto, se aborda la intervención en el presbiterio, el espacio cultual más transformado y desconocido de la iglesia, como evidenciaba la superposición de actuaciones a veces no complementarias entre sí.

Por cuestiones de mínima intervención y de manera consensuada con los promotores del Convenio, se acordó mantener el frente de mármol rojo bajo el retablo del altar mayor, reponer el zócalo de mármol rojo en los laterales de las puertas de paso y reintegrar con estucos la parte baja de las pilastras de conexión con la nave. Estas decisiones afectaron también a algunas actuaciones previstas en las tribunas, que pasaron a estar de forma permanente en comunicación directa con el altar, para evidenciar las nuevas condiciones espaciales y de iluminación natural. El presbiterio ha pasado de ser una escenografía plana y oscura con el retablo como telón de fondo a ser un elemento tridimensional debido a la nueva entrada de luz tangencial a nivel de tribunas (en correspondencia con las demás de la nave) y la contribución cromática de los paramentos laterales (en referencia a la antigua mesa de altar). Por limitaciones de presupuesto, ha sido preciso renunciar al mobiliario del proyecto, manteniéndose tan sólo aquellos elementos imprescindibles para la celebración de la liturgia: la mesa de altar y una escalera portátil de acceso al sagrario. Dado que no era posible trasladar la anterior mesa de altar de mármol rojo, se decidió forrarla con listones de madera maciza de haya, dejando a la vista la sacra. Se optó por esta madera ya que posee unas vetas y tono similares a la madera de álamo negro de las puertas de comunicación del presbiterio.

Pensamos que el conjunto de estas actuaciones ha dignificado el espacio cultual de mayor carga simbólica. 
PROCESO DE INTERVENCIÓN EN EL INTERIOR
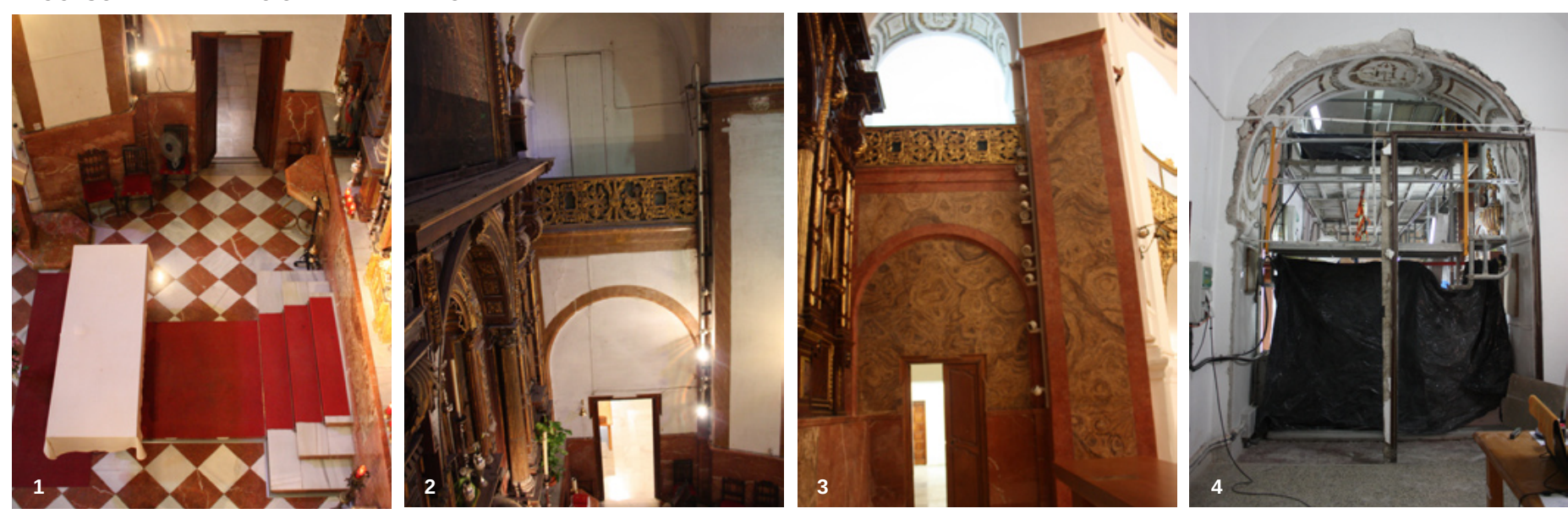

Actuaciones en el presbiterio | fotos Fondo Gráfico IAPH (Aurora Villalobos Gómez: 1, 2, 3, 4, 6, 7; José Manuel Santos Madrid: 5, 8)
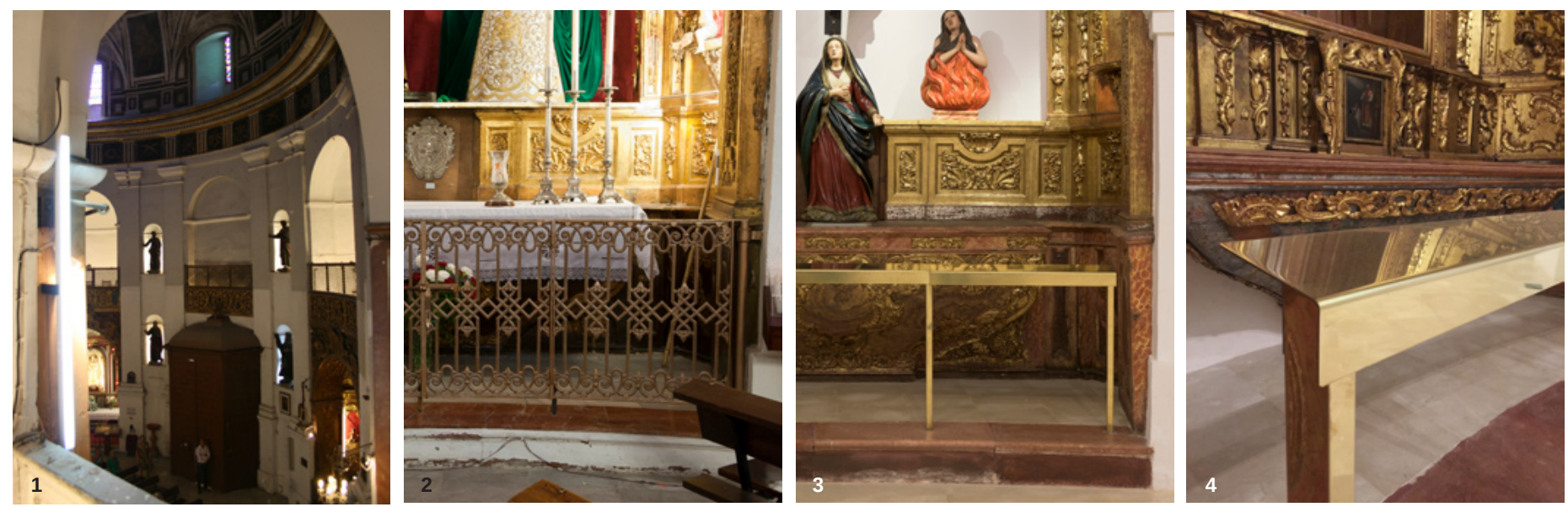

Ordenación de los elementos muebles | fotos Fondo Gráfico IAPH (J. M. Santos Madrid: 2, 3, 5, 7; A. Villalobos Gómez: 1, 4, 6, 8)
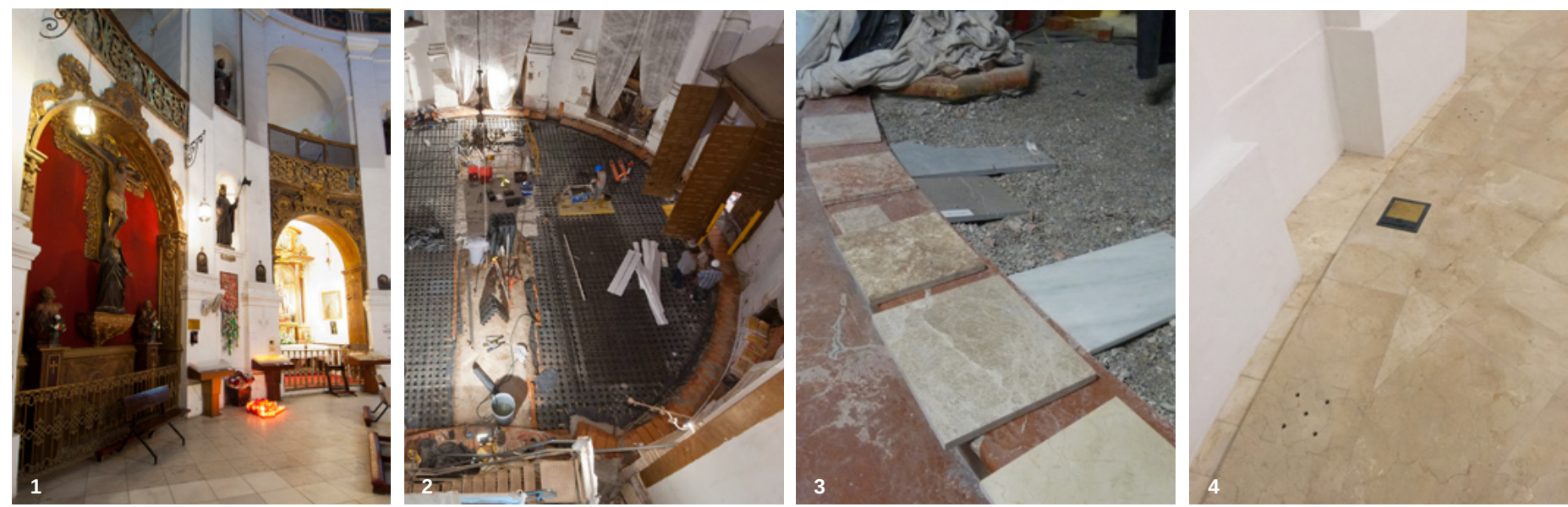

Adecuación funcional con nueva solería y vidrieras | fotos Fondo Gráfico IAPH (J. M. Santos Madrid: 1, 2, 6; Teresa Morillo Romero: 3; A. Villalobos Gómez: 4, 5; Javier Hijano Fernández: 7; Manuel M. ${ }^{a}$ de Cárdenas Mansfel: 8) 

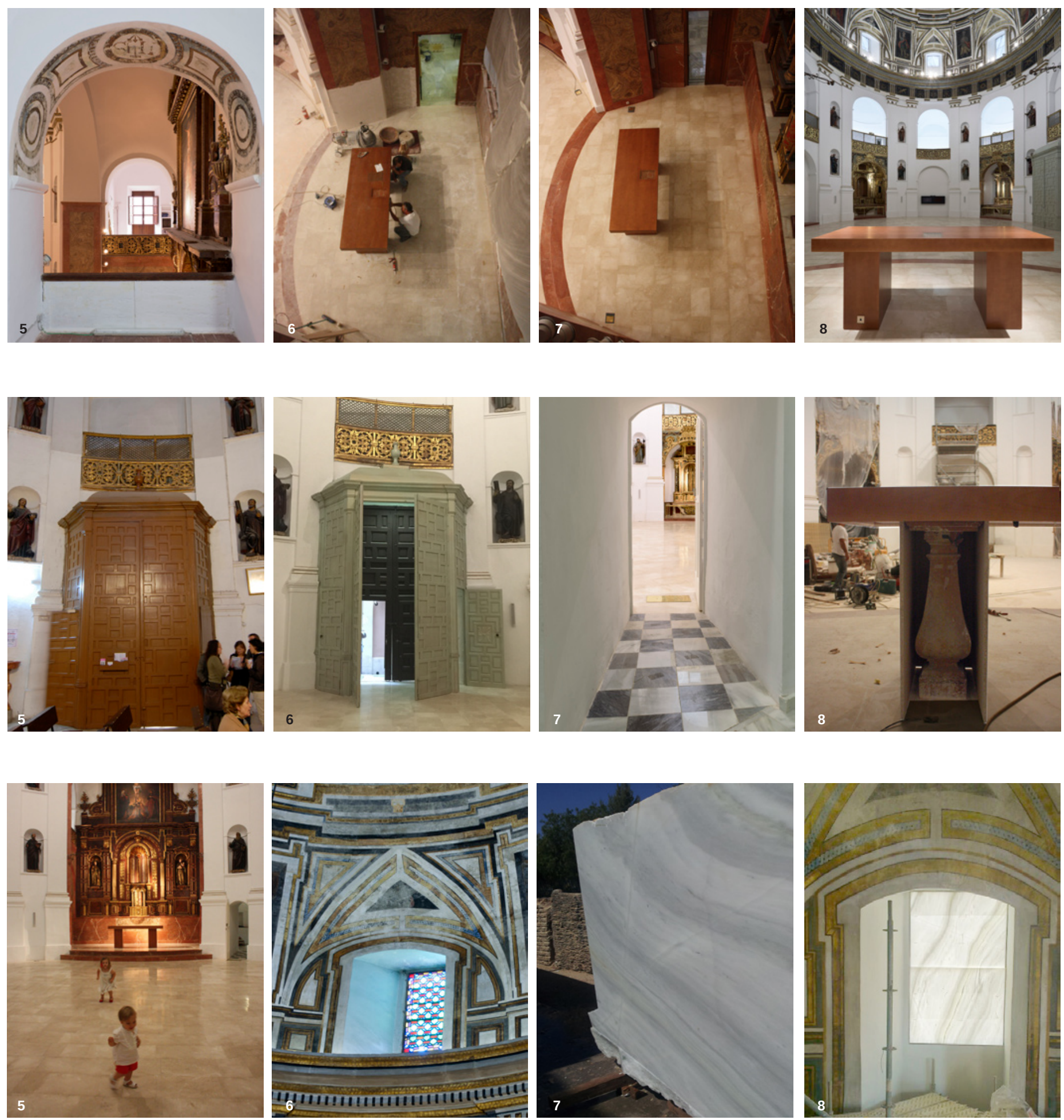


\section{MÁS ALLÁ DE LA OBRA}

\section{Resultados del proyecto}

La ejecución de este proyecto ha supuesto, en primer lugar, una mejora de las condiciones de conservación, uso y exposición de los bienes culturales, en el sentido no sólo de conservar su materialidad sino de actualizar sus valores culturales; por aquello de que no deja de ser una intervención contemporánea que desea recuperar la memoria del edificio en toda su complejidad.

Por supuesto ha incrementado el valor cultural de la iglesia con un patrimonio desconocido, desvelando lo que aparentemente estaba visible (tridimensionalidad del presbiterio, capillas dispuestas en las diagonales, umbrales como límite entre modos de uso, continuidad entre tribunas de la nave y presbiterio...) y descubriendo algunos elementos que habían quedado ocultos (arco decorado de la capilla doméstica, pinturas imitando ónice y tribunas en el presbiterio, hueco de paso al antiguo patio, marmoreados en portada, bicromía de la fachada...).

Esto ha conllevado a su vez compatibilizar las necesidades de los bienes

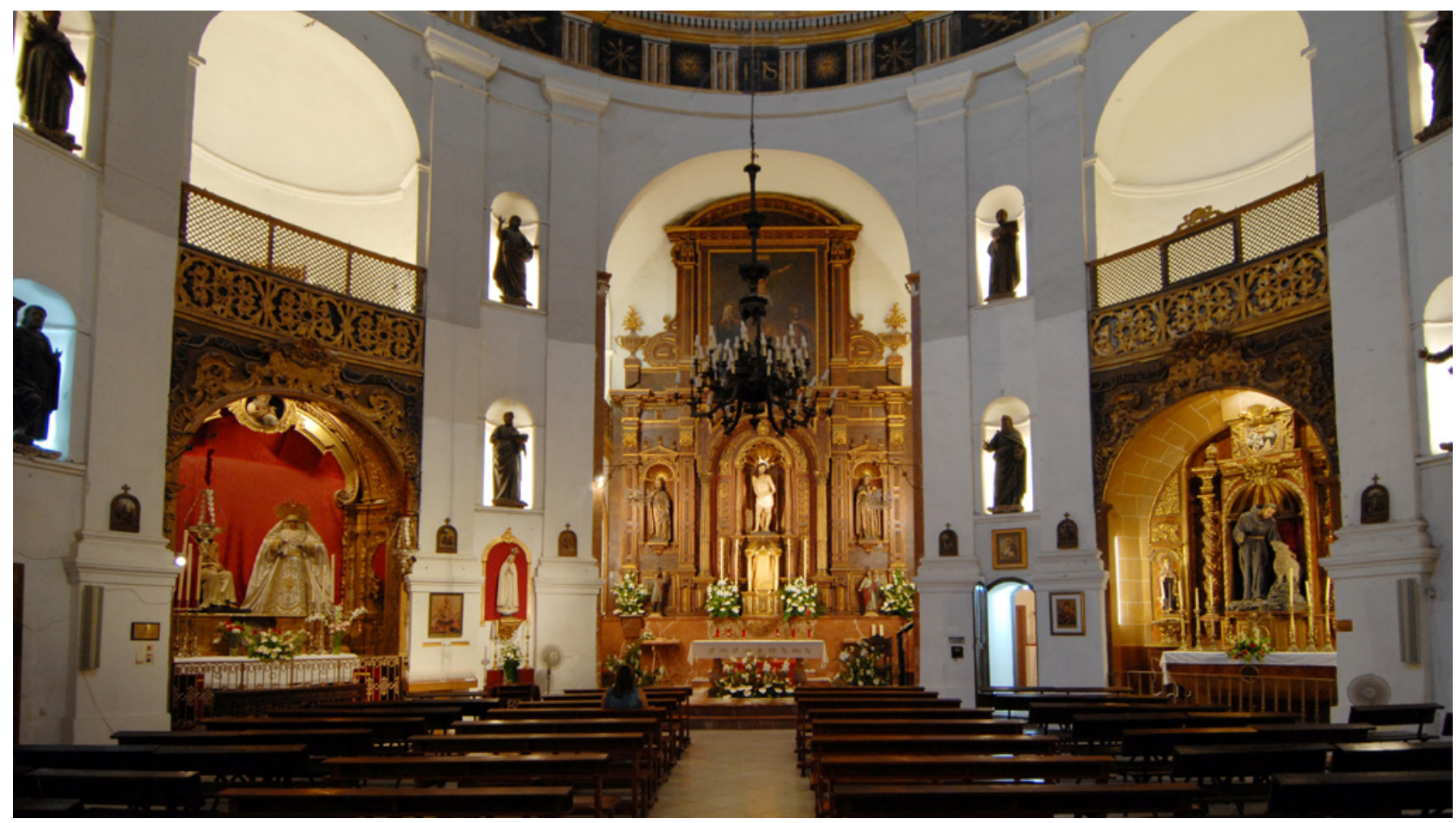


sables de su uso o beneficiarios de su disfrute; mejorando la experiencia cotidiana (cultual y cultural); y dando facilidades para el mantenimiento (nuevo sistema de registro de la cámara entre cubierta, instalación eléctrica de servicio en la subida a la torre, nueva escalera de acceso a la galería perimetral).

Para garantizar la calidad de la intervención la toma de decisiones dentro del equipo técnico ha sido tomada de manera coherente con los resultados de los estudios, y coordinada entre los dos equipos; ha estado sujeta al consenso de la Comisión Técnica de Obras donde tenían presencia todos los miembros del Convenio para velar por el cumplimiento; y se ha sometido al dictamen de la Comisión Provincial de Patrimonio para su validación, incorporando las observaciones oportunas.

Además, ha sido un ejercicio constante y consciente de transparencia, no sólo hacia las instituciones referidas sino hacia la sociedad que es la que debe comprender las soluciones adoptadas, por medio de un Plan de comunicación y difusión que ha desarrollado acciones online (web, blog, redes sociales), para público en general (visitas didácticas, obra abierta) y especializado (jornadas técnicas y publicaciones científicas).
Interior de la iglesia. Estado final | foto Fondo Gráfico IAPH (José Manuel Santos Madrid)

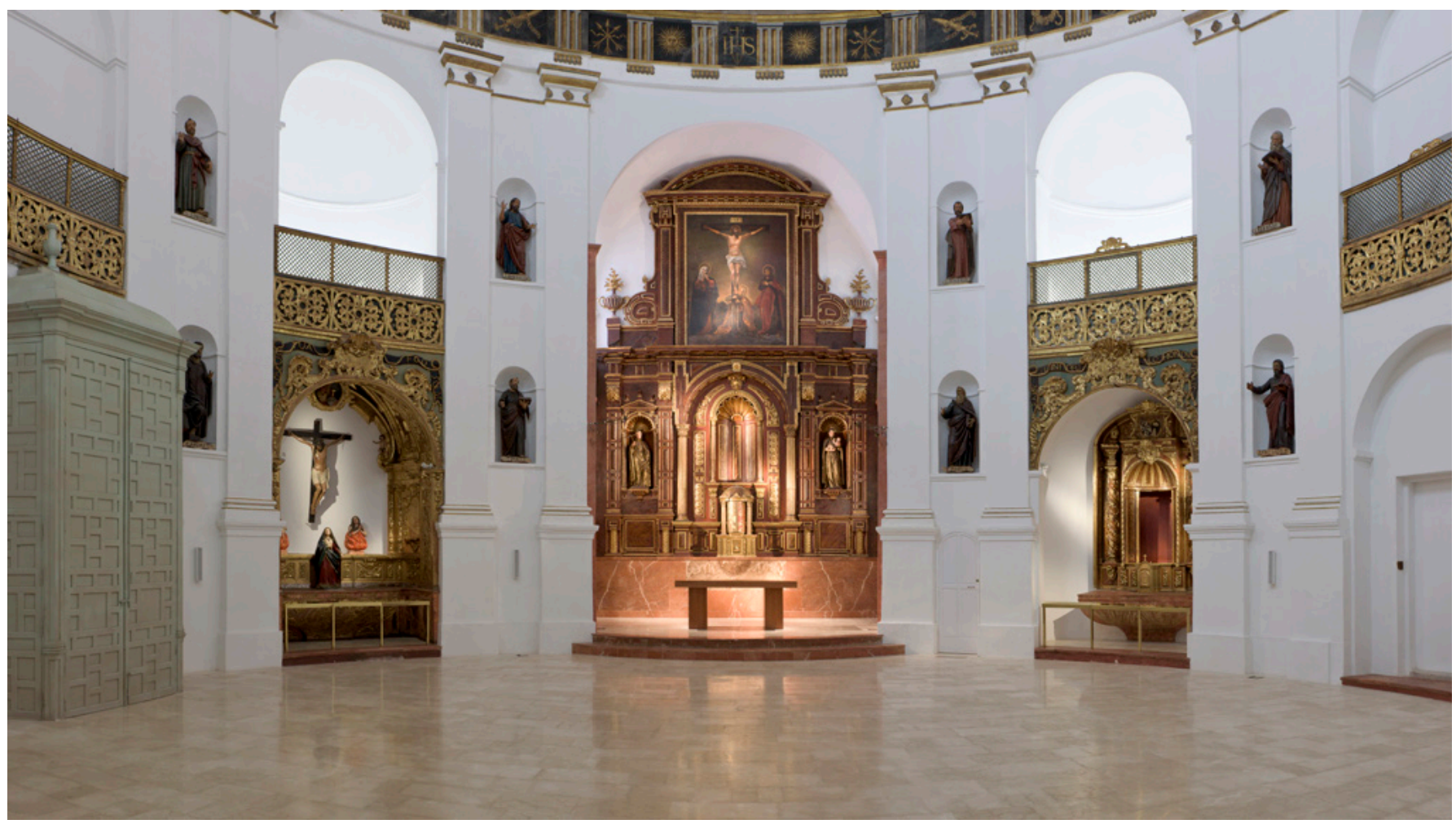



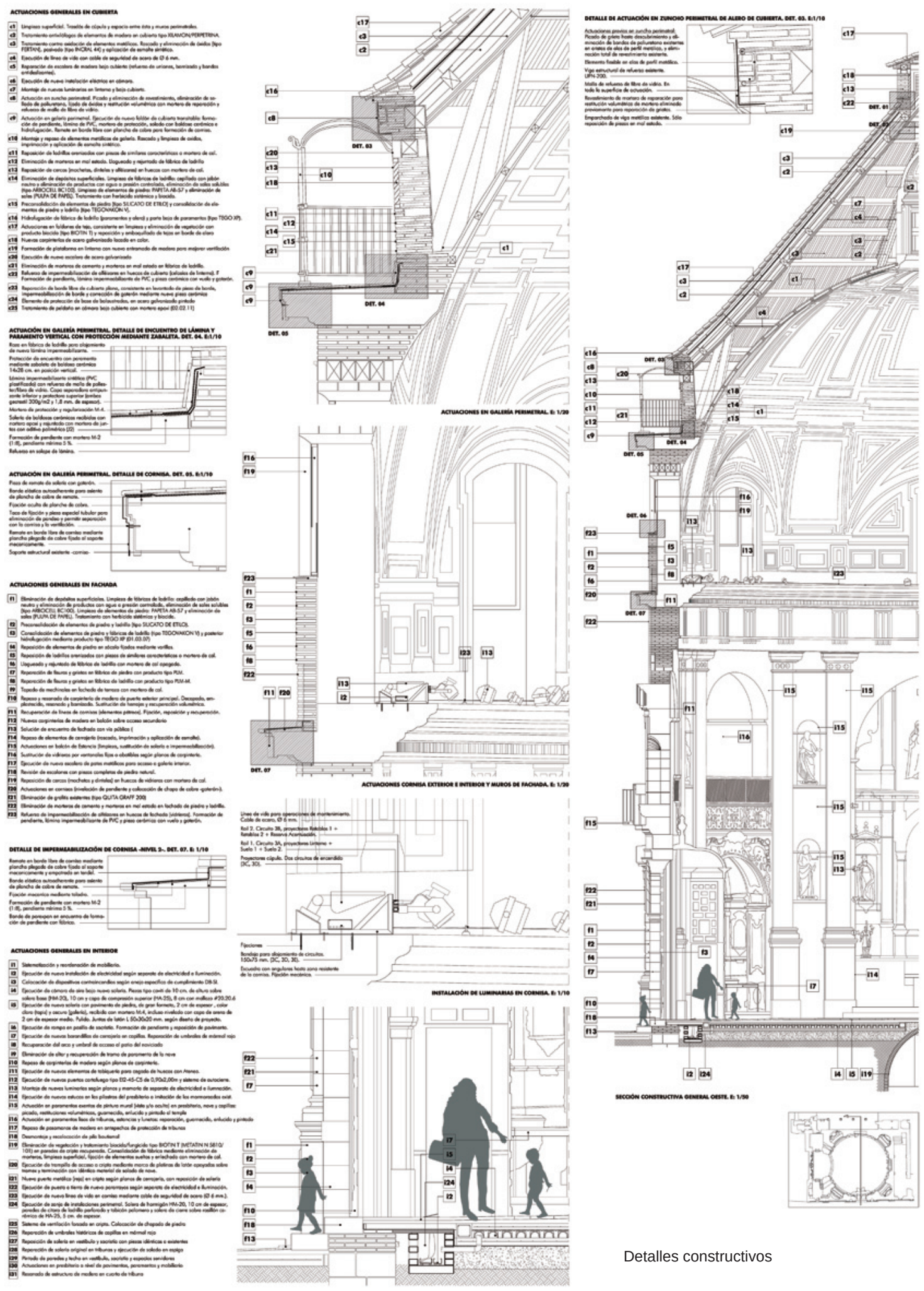

Detalles constructivos 


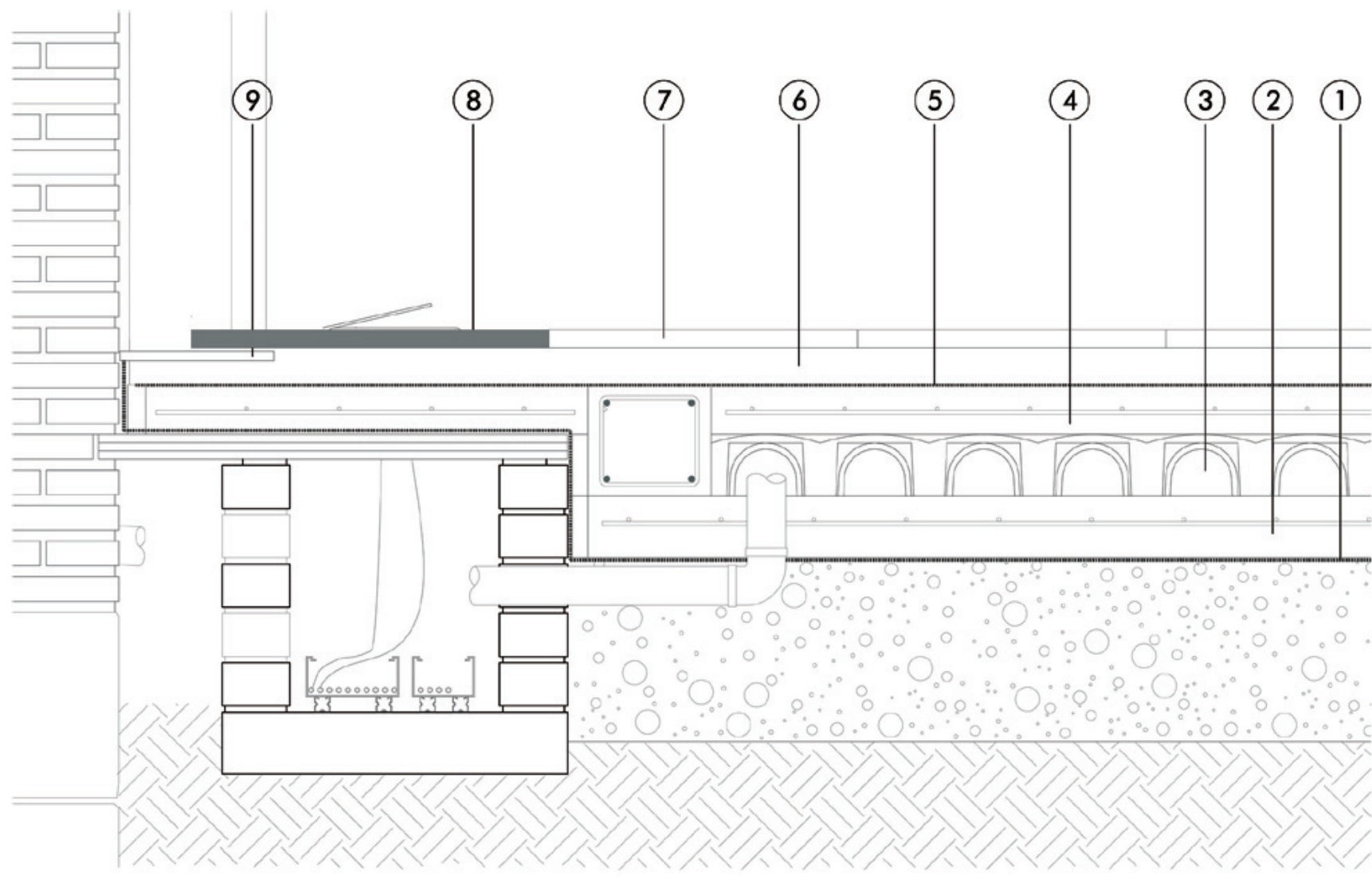

ACTUACIÓN EN SOLERÍA VENTILADA Y ZANJA PERIMETRAL DE INSTALACIONES

(1) Lámina de polietileno de separación entre gravilla y solera base.

(2) Solera base para apoyo de entramado de ventilación tipo Cóviti, de HM-20 y $10 \mathrm{~cm}$. de espesor, con armadura de reparto \#20.20.6.

(3) Entramado de ventilación bajo solería de nave formado por piezas de encofrado tipo Cáviti C-10, de $10 \mathrm{~cm}$. de altura.

(4) Capa de compresión superior de HM-20 y $8 \mathrm{~cm}$. de espesor, con armadura de reparto \#20.20.6.

(5) Lámina de polietileno de separación entre soporte y capa de arena de regularización.

(6) Capa base de arena fina limpia de río para regularización de soporte, $30-50 \mathrm{~mm}$. de espesor, con un contenido máximo de materia orgónica, arcillas o limos del 1\%, y diámetro móximo $5 \mathrm{~mm}$., y capa de agarre mediante mortero de cemento cola de de dosificación 1:3 y espesor aproximado $20 \mathrm{~mm}$

(7) Solería de piezas de mármol de $30 \mathrm{~mm}$. de espesor, tamaño y modelo a elegir por la Dirección Facultativa, en nove principal. Colocación según diseño de proyecto sobre mortero de ogarre de cemento cola.

(8) Piezas especiales de mármol de $30 \mathrm{~mm}$. de espesor, para formación de dibujo perimetral de nave. Corte curvo de piezas para formación de corona circular perimetral, con inclusión en determinadas piezas de elementos de electricidad e iluminación.

(9) Piezas de mármol en transición solería-muro de $15 \mathrm{~mm}$. de espesor, dispuestas a cota inferior que resto de solería de la nave, sobre las que se apoyan las piezas especiales que conforman el dibujo perimetral. 


\section{Transferencia de conocimiento}

Los resultados del proyecto de intervención también trascienden del propio edificio conforme a la visión del IAPH de ser referente en investigación, desarrollo e innovación en materia de patrimonio cultural. Es por eso que también el proyecto aporta: el planteamiento de nuevas líneas de investigación (sobre todo aquellas cuestiones del estudio histórico que trascienden las necesidades concretas del proyecto o sobre técnicas de análisis no destructivo); el desarrollo de la figura de intervención del Proyecto de conservación, como herramienta metodológica y operativa (sistematizando una estrategia común para bienes muebles e inmuebles); la normalización de los contenidos del Proyecto básico y de ejecución (conciliando las exigencias en patrimonio cultural con la legislación edificatoria) y la sistematización de los procesos de intervención (generando una documentación normalizada, protocolos de trabajo, glosario, leyenda de patologías).

De este modo el IAPH ha acometido por primera vez la intervención integral en un bien inmueble con un conjunto de bienes muebles asociados adoptando una fórmula de gestión directa como garantía de calidad del proceso de redacción-licitación-ejecución de las intervenciones, que lo posiciona entre las demás instituciones dedicadas al patrimonio cultural.

\section{Recursos para el futuro}

El propio Proyecto de conservación se convierte en el primer documento de referencia para futuras intervenciones. Los estudios previos contienen una exhaustiva documentación técnica válida como registro gráfico (reportaje fotográfico), soporte de trabajo (planimetría actualizada), referencia del estado de equilibrio higrotérmico (registro de mediciones de humedad-temperatura de las sondas) y del criterio de ordenación de los bienes muebles (inventario de bienes muebles con valor cultural y cultual como herramienta de filtro).

A esto se añadiría toda la documentación generada en la obra (actas, informes, memorias, certificaciones, fichas, nuevos planos), sistematizada en la Memoria final como un ejercicio de responsabilidad hacia el futuro.

Y por último, se aporta el Libro del edificio como un documento vivo a disposición de los propietarios que facilite el uso correcto de los espacios, actividades y elementos constructivos (precauciones, prescripciones y prohibiciones) y el adecuado mantenimiento del edificio (por el usuario o profesional cualificado). De él destacaríamos algunas de las medidas propuestas para la conservación del programa iconográfico, ya que se trata no sólo de conservar los elementos materiales sino también los valores intangibles: 
$>$ Mantener como capillas sólo los cuatro ámbitos dispuestos históricamente en las diagonales de la nave.

> Respetar el vacío del antiguo hueco de paso al patio del noviciado como tal, no invadiendo su umbral ni confiriéndole un nuevo uso, para poder mantener la lectura del eje de acceso frente a la calle.

> Respetar el vacío frente al presbiterio, tanto en planta como en alzado.

$>$ Respetar las tribunas del presbiterio como espacios sin uso que sirven para una mejor comprensión espacial; así como las limitaciones de uso de las demás tribunas de la nave.

$>$ No volver a trazar cables vistos ni realizar perforaciones en los paramentos de la nave ni usar velas de combustión en la nave de la iglesia y capillas por cuestiones de seguridad en caso de incendio.

$>$ Unificar el diseño de la señalética que se incorpore a las capillas para evitar de nuevo la contaminación visual, haciendo uso de los pasamanos de las barandillas; dejando de emplear el cancel como soporte de información.

> Mantener en el mobiliario que se incorpore el tono de la madera presente en la nueva mesa de altar del presbiterio y distribuirlo en planta de manera holgada para que no se agote el espacio disponible y quede un generoso pasillo perimetral de circulación.

De este modo se garantiza el buen comportamiento de la intervención con un mantenimiento constante y adecuado. Comienza una nueva vida en el edificio donde se compatibilizan las necesidades de conservación de los bienes con las prestaciones a los usuarios por medio del orden, el aire y la luz. Desde la contemporaneidad se recupera de su memoria lo que estaba oculto para explicitar sus valores culturales y pasarlos en las mejores condiciones a las generaciones venideras.

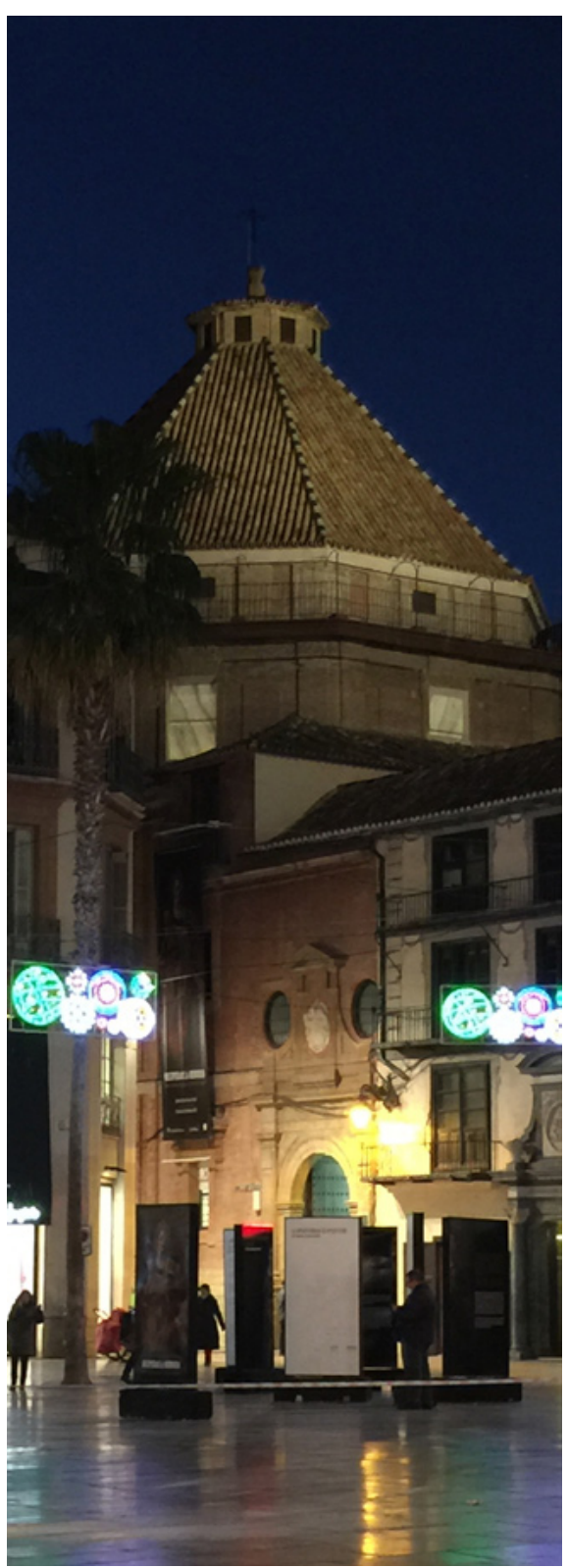

Vista nocturna desde la Plaza de la Constitución foto Fondo Gráfico IAPH (Aurora Villalobos Gómez) 


\section{FICHA TÉCNICA DEL PROYECTO}

\section{PROMOTORES}

Convenio de colaboración para la restauración de la Iglesia del Santo Cristo de la Salud de Málaga. 17 de septiembre de 2009

> Junta de Andalucía. Consejería de Cultura. Dirección General de Bienes Culturales y Museos e Instituto Andaluz del Patrimonio Histórico

> Fundación Montemadrid

> Obispado de la Diócesis de Málaga

\section{DIRECCIÓN DEL PROYECTO}

Román Fernández-Baca Casares, director del Instituto Andaluz del Patrimonio Histórico

\section{COORDINACIÓN GENERAL}

Lorenzo Pérez del Campo, jefe del Centro de Intervención en el Patrimonio Histórico

\section{COORDINACIÓN ESTUDIOS ANALÍTICOS}

Rosario Villegas Sánchez, responsable de la coordinación científica del Programa de Investigación de los Laboratorios y Análisis del IAPH

\section{COORDINACIÓN TÉCNICA CONSERVACIÓN}

$>$ Araceli Montero Moreno, restauradora

> Marta García de Casasola

Gómez, arquitecta

\section{COORDINACIÓN DE GRUPOS}

$>$ M. ${ }^{a}$ del Mar González González, restauradora
> Aurora Villalobos Gómez, arquitecta

\section{EQUIPO TÉCNICO}

Redacción y Dirección Técnica del Proyecto de conservación de bienes muebles

> M. ${ }^{\text {a }}$ del Mar González González, restauradora

> Fernando Guerra Librero, arquitecto-restaurador

Estudios medioambientales

$>$ Raniero Baglioni, técnico en conservación preventiva

> Salvador Valpuesta Trujillo, colaborador, estancia en prácticas

$P$. de intervención en el inmueble Redacción y Dirección de las Obras del Proyecto básico y de ejecución de intervención en el inmueble > Aurora Villalobos Gómez, arquitecta

> Marta García de Casasola Gómez, arquitecta

> Román Fernández-Baca Casares, arquitecto

Asesores durante la ejecución de las obras

$>$ Ana Bouzas Abad, restauradora

> Ángel Luis León Rodríguez, arquitecto, ESTIN SC arquitectos > Pablo Pastor Vega, arquitecto técnico

Redacción y dirección del Proyecto de andamios, instalaciones $y$ medios auxiliares

> Manuel de Cárdenas Mansfeld, arquitecto técnico, a de c integral de proyectos
> Mariano Asuero Orta, arquitecto técnico, a de $\mathrm{c}$ integral de proyectos > Fernando Serrano Gaviño, arquitecto, a de c integral de proyectos

Redacción y Coordinación del Estudio de seguridad y salud > Manuel de Cárdenas Mansfeld, arquitecto técnico, a de $\mathrm{c}$ integral de proyectos

$>$ Mariano Asuero Orta, arquitecto técnico, a de c integral de proyectos > Fernando Serrano Gaviño, arquitecto, a de c integral de proyectos

\section{Ejecución de las Obras}

> Manuel de Cárdenas Mansfeld, arquitecto técnico, a de c integral de proyectos

$>$ Mariano Asuero Orta, arquitecto técnico, a de c integral de proyectos

\section{Colaboradores}

$>$ Teresa Morillo Romero, arquitecta

$>$ Antonio A. Carrasco Delgado, arquitecto, estancia en prácticas > Estela Quintero Peralías, arquitecta, estancia en prácticas

Proyecto de Actividad Arqueológica de Control de Movimientos de Tierra Yolanda González-Campos Baeza

\section{Estudios de técnicas de examen por imagen \\ > Eugenio Fernández Ruiz, fotógrafo \\ > José Manuel Santos Madrid, fotógrafo \\ > Juan Carlos Cazalla Montijano, fotógrafo}

+ info: <http://www.iaph.es/web/canales/proyectosantocristo> <http://santocristomalaga.blogspot.com.es/> 


\section{Levantamiento planimétrico}

> José Manuel López Sánchez, responsable levantamiento $2 \mathrm{D}, \mathrm{TCA}$ geomática

> José Luque Bellido, responsable modelado 3D e infografía, arquitecto, Plan9

\section{Estudio histórico}

> José Luis Gómez Villa, historiador del arte

> Igor Vera Vallejo, historiador del

arte

> Sara Martín Asensio,

documentalista

\section{Estudios analíticos}

> Jesús Espinosa Gaitán, geólogo

> Marta Sameño Puerto, bióloga

> Víctor Menguiano Chaparro,

biólogo

> Lourdes Martín García, química

> Auxiliadora Gómez Morón, química

> Abel Bocalandro Rodríguez, químico

> Elena Revuelta Camacho, ingeniera industrial

\section{Comunicación}

> Antonio Martín Pradas, periodista e historiador del arte

$>$ Ana Almagro Vidal, arquitecta

> Luisa Loza Azuaga, arqueóloga

$>$ Millán Herce, fotógrafo

> Beatriz Castellano Bravo, arquitecta

$>$ En Pie Producciones, diseño gráfico: diseño grafico, producción y montaje de la exposición

\section{Empresa Adjudicataria de las Obras. BAUEN CONSTRUCTORA}

> José Manuel Barreiro Avellaneda, delegado

> Javier Hijano Fernández, jefe de obras

\section{Equipo restauradores IAPH}

$>$ M. ${ }^{a}$ Esther Albendea Ruz

> Carmen Ángel Gómez

$>$ Amalia Cansino Cansino

$>$ Antonio Díaz Arnido

> Lourdes Fernández González

> Antonio Custodio López García

$>$ Rocio Magdaleno Granja

> Manuel Ángel Martínez Montiel

$>$ M. ${ }^{\text {a }}$ Teresa Martínez Mateo

> José Morillo García

> Lourdes Núñez Casares

$>$ Beatriz Prado Campos

$>$ M. ${ }^{\text {a }}$ Teresa Real Palma

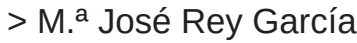

$>$ Constanza Rodríguez Segovia

$>$ Cinta Rubio Faure

> Antonio Jesús Sánchez

Fernández

> Mónica Santos Navarrete

\section{COMISIÓN TÉCNICA DE PROYECTOS Y OBRAS}

> Román Fernández-Baca Casares, director del Instituto Andaluz del Patrimonio Histórico

$>$ Gabriel Morate Martín, director del Departamento de Conservación, Fundación Montemadrid > José Cuaresma Pardo / María José García García, Jefe/a del Servicio de Conservación y Obras del Patrimonio Histórico, Dirección General de Bienes Culturales y Museos, Consejería de Cultura > Javier Arcas Cubero, asesor jurídico del Obispado de la Diócesis de Málaga
> Lorenzo Pérez del Campo, jefe del Centro de Intervención del IAPH > Ana Almagro Vidal, Departamento de Conservación, Fundación Montemadrid

\section{FE DE ERRORES}

En la versión del artículo "La memoria del tiempo o el proceso de intervención en la iglesia del Santo Cristo de la Salud de Málaga", publicada el 26 de octubre de 2015 , se omitía por error en la ficha técnica del proyecto (pp. 218-219) el nombre y la responsabilidad de Yolanda González-Campos Baeza.

Dicha omisión aparece corregida en esta versión de 30 de octubre de 2015.

+ info: <http://www.iaph.es/web/canales/proyectosantocristo> <http://santocristomalaga.blogspot.com.es/> 